Research Article

\title{
Estimating the Asphalt Binder Film Thickness Using Scanning Electron Microscope and Energy Dispersive X-Ray Spectroscopy
}

\author{
Fazli Karim (D), Jawad Hussain (D), and Imran Hafeez (D) \\ Taxila Institute of Transportation Engineering, University of Engineering and Technology, Taxila, Pakistan \\ Correspondence should be addressed to Fazli Karim; engr_fazli@yahoo.com
}

Received 23 September 2020; Revised 27 March 2021; Accepted 2 April 2021; Published 19 April 2021

Academic Editor: Shazim A. Memon

Copyright (c) 2021 Fazli Karim et al. This is an open access article distributed under the Creative Commons Attribution License, which permits unrestricted use, distribution, and reproduction in any medium, provided the original work is properly cited.

\begin{abstract}
Asphalt binder film thickness has relation to mixing temperature and binder content in hot mix asphalt, which influences mixture's performance. A significant variation in assessing the asphalt binder film thickness has been observed in the literature. Development of state of the art technology and Superpave specification requires the study of actual asphalt binder film thickness at micro-level. This study estimates asphalt binder film thickness at micro-level and compares results with those obtained through analytical models from the previous studies. The study utilizes different asphalt mixtures at various mixing temperatures and binder contents. The asphalt binder film thickness around the finest particles of $500 \mathrm{~nm}$ ( 0.5 micron) size in asphalt mastic was detected and measured by image analysis (using scanning electron microscope) and elemental analysis (using energy dispersive $\mathrm{X}$-ray spectroscopy) at magnifying power of $\times 30,000$. The analytical estimation revealed that the asphalt binder film thickness for the aforementioned conditions varies from $9 \mu \mathrm{m}$ to $13 \mu \mathrm{m}$, with a fair relationship to binder content and mixing temperature. However, results obtained from image analysis revealed that the asphalt binder film thickness varies from $0.5 \mu \mathrm{m}$ to $2.4 \mu \mathrm{m}$, with no relation to binder content and mixing temperature. The image analysis showed that the asphalt mixtures mostly contain asphalt mortar and asphalt mastic, occurring in irregular shape. It was also found that the asphalt binder film does exist as a separate entity inside the asphalt mastic in the form of a band around the filler particles as non-absorbed binder, which fills the approximate distance of 0.5 to 2.5 microns among filler particles.
\end{abstract}

\section{Introduction}

The term "asphalt binder film thickness" when applied to the hot mix asphalt (HMA) refers to the thickness of the effective asphalt binder used to effectively lubricate and produce a coat on the aggregate surface in asphalt mixture. The asphalt binder film thickness is often mentioned in the literature as mix design and quality assurance criteria to withstand traffic and environment. Over the years, a general concept suggested that an average asphalt binder film thickness, ranging from 8 to 15 microns, will provide acceptable pavement performance [1]. Although this concept of the asphalt binder film thickness sort of makes sense but the reality as found by image analysis in the current study is a different story, suggesting that the concept of film thickness as design criteria is nothing more but just a notion. HMA is a composite material made up of coarse aggregate, fine aggregate, filler, binder, and air voids. The durability of HMA is dependent upon many factors among which the volumetric properties such as voids in mineral aggregates (VMA) and air voids (AV) are significant. The minimum VMA is used as design criteria in asphalt mixtures since late 1950s, but difficulties in achieving VMA in Superpave ${ }^{\circledR}$ mixtures have led to several new studies. Therefore, some researchers recommend the average asphalt binder film thickness as design criteria in asphalt mixtures rather than minimum VMA in Superpave volumetric mix design $[2,3]$. An experiment controlling the asphalt film thickness was designed in order to establish a relationship between asphalt film thickness and the molding load. The shear test was carried out to study the behavior of the failure mechanism at the interface between aggregate and asphalt under different binder films. It was concluded that an inadequate asphalt binder film thickness 
at the interface is responsible for shear failure [4]. It was also reported that the asphalt binder film on the aggregate surface in compacted asphalt mixture is the source of cohesion and adhesion, thereby affecting bonding performance in terms of durability of asphalt mixtures [2]. In addition to these adhesion-based theories in asphalt mixtures, the mechanical properties of the asphaltaggregate interfacial adhesion subjected to shear and tensile loads were also investigated experimentally [5-8]. The asphalt binder film in asphalt mixture is related to three failure mechanisms including cohesive failure (asphalt internal failure), adhesive failure (interfacial zone failure), and aggregate failure [9]. However, the influence of the asphalt binder film thickness on the performance of asphalt pavements is usually ignored, particularly when the performance does not meet specifications. Thus, it is necessary to deeply understand the effect of asphalt binder film thickness on the mechanical properties of compacted asphalt mixtures. A test method was designed in order to study a thin film of asphalt between a cylindrical rock core and a metallic stub having a controlled geometry using a modified micrometer. The method of "density grading mixture" was used to calculate average asphalt binder film thickness in asphalt mixture design where the film thickness ranged from 8 to $10 \mu \mathrm{m}$ [10]. Alkofahi and Khedaywi evaluated the relation between asphalt film thickness and stripping resistance for loose and compacted asphalt mixtures using Texas boiling test. Their results showed that the asphalt film thickness depends on many factors such as type of aggregates, the total surface area of the aggregates, asphalt binder content in the asphalt mixture, and the degree and moisture susceptibility period as well. It was concluded that asphalt mixtures having an average asphalt film thickness of $9-11 \mu \mathrm{m}$ have higher stripping resistance [11]. An adequate thickness of asphalt film around the aggregate in asphalt mixture acts as interface bonding agent or adhesion promoter, which is required for adequate bonding in order to make asphalt mixture rutresistant against high temperature, crack-resistant against low temperature, fatigue resistant, and water resistant. A minimum film thickness ranging from $6-8 \mu \mathrm{m}$ was recommended for adequate performance of HMA, but no background research data are available to support these minimum values [12]. The coarser asphalt mixtures have thick asphalt film due to lower surface area but commonly fail to meet the minimum VMA criteria. Similarly, fine asphalt mixtures have lower asphalt film due to higher surface area and commonly meet the minimum VMA criteria. Therefore, a modification to the Superpave VMA criteria is recommended for adequate mixture design in order to ensure mixture's durability. Hence, the minimum VMA requirement as per Superpave method of mix design, which is based on minimum asphalt content, is required to be based on a minimum asphalt film thickness. It is also recommended that the asphalt film thickness and surface area factor for coarser and finer sieves are required to be measured by modern tools [2]. McLeod [13] also concluded that the asphalt mixtures are required to be designed on the basis of an average asphalt film thickness of $8 \mu \mathrm{m}$ rather than minimum asphalt content. A lot of variations in asphalt binder film thickness have been observed in the literature, as shown in Table 1.

The two critical steps involved in estimating asphalt binder film thickness analytically are to estimate the effective volume of the asphalt binder and to calculate total surface area of aggregates used in asphalt mixtures. Hveem used an appropriate set of surface area factors to relate aggregate gradation to the total surface area of aggregates [18]. These factors are put forward in the Asphalt Institute (AI) Manual, series no. 2 (MS-2) (2012), as presented in Table 2.

Analytical models to estimate average asphalt binder film thickness in HMA are provided in Table 3.

To date, estimation of asphalt binder film thickness in HMA is based on various analytical models, as presented in Table 3. These models are based on surface area factors of aggregates where the aggregates gradation is linked to its total surface area based on certain assumptions. These assumptions are the spherical shape of aggregates, uniform binder film thickness on them, and no information on porosity, and degree of compaction of the mixture. Therefore, due to discrepancies in relating gradation to total surface area of aggregates based on surface area factors, a lot of variations in asphalt binder film thickness have been observed in the literature, as shown in Table 1 . However, in the last few decades, due to development in state of the art equipment and Superpave specifications, the behavior of asphalt binder was studied on microlevel in order to predict its actual performance. Thus, viscosity was declared an important criterion for mixture's performance, as viscosity of the binder is dependent on temperature which greatly affects asphalt binder film thickness in HMA. To the author's knowledge, asphalt binder film thickness was not studied on microlevel. Therefore, this study is aimed at investigating the asphalt binder film thickness around the finest particles of $500 \mathrm{~nm}$ ( 0.5 micron) size in asphalt mastic in HMA, at the highest magnification, using scanning electron microscope and energy dispersive X-ray spectroscopy.

\section{Objectives}

The main objectives of this study are

(1) To estimate the asphalt binder film thickness using analytical models for asphalt mixtures prepared at various mixing temperatures and binder contents

(2) To measure asphalt binder film thickness around the finest particles in asphalt mastic using image analysis SEM and EDS in order to verify film thickness calculated in step (1)

(3) To determine the effect of asphalt binder content and mixing temperature on asphalt binder film thickness at microlevel and asphalt mixture's performance, using analytical equations and image analysis. 
TABLE 1: Recommended asphalt binder film thicknesses for HMA.

\begin{tabular}{lc}
\hline Film thickness $(\mu \mathrm{m})$ & Author \\
\hline $8 \mu \mathrm{m}$ (avg.) & McLeod [13] \\
$8-15 \mu \mathrm{m}$ & Roberts et al. [1] \\
$9-10 \mu \mathrm{m}(\mathrm{min})$ & Kandhal et al. [12] \\
$\begin{array}{l}6-8 \mu \mathrm{m} \text { (min) (no background research data is available to support these recommended minimum values) } \\
9-10 \mu \mathrm{m} \text { at } 8 \% \text { air voids }\end{array}$ & Kandhal and Chakraborty [14] \\
$9-10$ (optimum) & Sengoz and Agar [15] \\
$9-15.5 \mu \mathrm{m}$ (based on index model) & Heitzman [16] \\
$8.5-13.5 \mu \mathrm{m}$ (based on virtual model) & Oliver [17] \\
$7.5 \mu \mathrm{m}$ (min) for minimum fatigue life of $70 \mathrm{k}$ cycles. & \\
$\begin{array}{l}\text { Film thickness has to be increased for higher fatigue lives of asphalt } \\
9-11 \mu \mathrm{m} \text { (avg.) for higher stripping resistance of asphalt }\end{array}$ & AlKofahi and Khedaywi [11] \\
\hline
\end{tabular}

TABLE 2: Asphalt Institute (AI) surface area factors.

\begin{tabular}{|c|c|c|c|c|c|c|c|c|c|c|c|c|}
\hline Sieve size $(\mathrm{mm})$ & +25 & 25 & 19 & 12.5 & 9.5 & 4.75 & 2.36 & 1.18 & 0.60 & 0.30 & 0.15 & 0.075 \\
\hline Surface area factors $\left(\mathrm{m}^{2} / \mathrm{kg}\right)$ & 0.41 & 0.41 & 0.41 & 0.41 & 0.41 & 0.41 & 0.82 & 1.64 & 2.87 & 6.14 & 12.29 & 32.77 \\
\hline
\end{tabular}

TABLe 3: Analytical models to estimate asphalt binder film thickness in HMA.

\begin{tabular}{lc}
\hline Analytical models to estimate asphalt binder film thickness in micron $(\mu \mathrm{m})$ & Description \\
\hline$F T_{b}=10^{5} P_{b e} / P_{s} \times G_{b} \sum \mathrm{SAF}_{i} \times P_{i}$ & Al-Khateeb [2] \\
$T_{F}=b /(100-b) \times\left(1 / \rho_{b}\right) \times(1 / \mathrm{SA})$ & Read and Whiteoak [19] \\
$\mathrm{DA}=P_{b e} \times 1000 /\left(\left(100-P_{b}\right) \times \gamma_{b} \times \mathrm{SA}\right)$ & Debao et al. [20] \\
$\mathrm{T}_{\mathrm{f}}=\left[\mathrm{W}_{\mathrm{b}} /(\mathrm{SA} \times 1000)\right] \times \mathrm{G}_{\mathrm{b}}$ & Zaniewski and Reyes [21] \\
$F=\left(10^{6} P_{b e} /\left(100-P_{b}\right)\right) \times(1 / \mathrm{SA}) \times\left(1 / \rho_{b}\right)$ & Road Note 19 TRL Ltd., UK [22] \\
$F_{b e}=981 \times P_{b e} / \mathrm{SST} \times\left(100-P_{b}\right)$ & Superpave series no. 2 (SP-2) [23] \\
\hline$F T_{b}, T_{\mathrm{F}}, \mathrm{DA}, T_{\mathrm{f}}, F$, and $F_{b e}$ stand for asphalt binder film thickness commonly measured in microns $\left(10^{-6} \mathrm{~m}\right)$ or $(\mu \mathrm{m})$. &
\end{tabular}

\section{Materials}

3.1. Aggregates. The virgin aggregates used in the current study were collected from Margalla Quarry, Pakistan, which is considered to be the largest aggregate quarry in the country. The physical properties of the aggregates are given in Table 4.

Petrographic analysis was carried out on aggregates as per the procedure described in ASTM C295 [33] to examine the quality, condition, and chemical stability of the individual constituents present in a solid intact mass. Petrographic examination is effectively used to identify specifically that part of aggregates which consist of weathered or otherwise altered aggregate particles. The petrographic analysis of Margalla aggregate used in the current study is given in Table 5 [34].

3.2. Asphalt Cement. The asphalt binder $60 / 70$ penetration grade was collected from Attock Refinery, located in Attock, Pakistan, and used in the current study. The physical characterization of the asphalt binder is provided in Table 6.

The modulus and phase angle were determined at a temperature ranging from $10^{\circ} \mathrm{C}$ to $82^{\circ} \mathrm{C}$, with an interval of $12^{\circ} \mathrm{C}$ and frequency of $0.1 \mathrm{~Hz}$ to $10 \mathrm{~Hz}$.

\section{Research Methodology}

A flow chart describing complete methodology of the current study is given in Figures 1 and 2. The primary phase consisted characterization of aggregate and bitumen by determining conventional index properties. Phase II includes Marshall mix design at various mixing temperatures and determining the optimum binder content (OBC) for each mixing temperature. Phase III comprises determination of asphalt binder film thicknesses at various mixing temperatures using analytical models provided in Table 3 and verification of the analytically estimated film thickness by image analysis using scanning electron microscope (SEM) and energy dispersive X-ray spectroscopy (EDS).

4.1. Marshall Mix Design. The current study is based on the laboratory work, conducted in the Highway and Transportation Engineering Laboratory, Taxila Institute of Transportation Engineering (TITE), Taxila, Pakistan. The aggregate blend was prepared according to the Asphalt Institute gradation (1994) for Asphalt Wearing Course, Class-A, with grain size distribution curve, as presented in Figure 3 . The conventional asphalt mixtures were prepared 
Table 4: Properties of Margalla aggregate.

\begin{tabular}{lcc}
\hline Property & Value & Specification limit \\
\hline Los Angeles abrasion value, (\%) ASTM C131 [24] & 21.5 & 30 (max) \\
Flakiness index, (\%) BS 933-3 [25] & 4.86 & 10 (max) \\
Elongation index, (\%) ASTM D4791 [26] & 2.4 & 10 (max) \\
Fractured particles (two faces), (\%) ASTM D5821 [27] & 100 & 90 (min) \\
Sand equivalent value, (\%) [28] & 77 & 50 (min) \\
Water absorption, (\%) ASTM C127 [29] & 1.04 & 2 (max) \\
Soundness of coarse aggregate, (\%) ASTM C88 [30] & 6.21 & 8 (max) \\
Soundness of fine aggregate, (\%) ASTM C88 [30] & 4.9 & 8 (max) \\
Uncompacted voids in fine aggregate, (\%) ASTM C1252 [31] & 48.5 & 45 (min) \\
Alkali silica reactivity, ASTM C586 [32] & Innocuous & - \\
Petrography, ASTM C295 [33] & Innocuous & - \\
\hline
\end{tabular}

Table 5: Petrographic composition of Margalla aggregate.

\begin{tabular}{lc}
\hline & Aggregate composition \\
\hline Calcite $=65 \%$ & Silica $=30 \%$ \\
Brown ore $=05 \%$ & Rock type: fine grained fossiliferous rock (fossiliferous limestone plane light) \\
\hline
\end{tabular}

Table 6: Properties of asphalt binder.

\begin{tabular}{lc}
\hline Property & Value \\
\hline Penetration at $25^{\circ} \mathrm{C},\left(1 / 10^{\text {th }}\right.$ of mm) ASTM D5 [35] & 64.5 \\
Softening point, $\left({ }^{\circ} \mathrm{C}\right)$ ASTM D36 [36] & 49 \\
Ductility, $(\mathrm{cm})$ ASTM D113 [37] & 101 \\
Flash point, $\left({ }^{\circ} \mathrm{C}\right)$ ASTM C142 [38] & 264 \\
Fire point, $\left({ }^{\circ} \mathrm{C}\right)$ ASTM C142 [38] & 288 \\
Viscosity at $135^{\circ} \mathrm{C},(\mathrm{Pa} \cdot \mathrm{s})$ ASTM D4402 [39] & 0.627 \\
Viscosity at $165^{\circ} \mathrm{C},(\mathrm{Pa} \cdot \mathrm{s})$ ASTM D4402 [39] & 0.170 \\
Complex modulus, G* (kPa) ASTM D7175 [40] & 32.2 \\
Phase angle, $\delta^{\circ}($ degree) ASTM D7175 [40] & 80.65 \\
$G * / \operatorname{Sin} \delta$ ASTM D6373 [41] & 32.63 \\
\hline
\end{tabular}

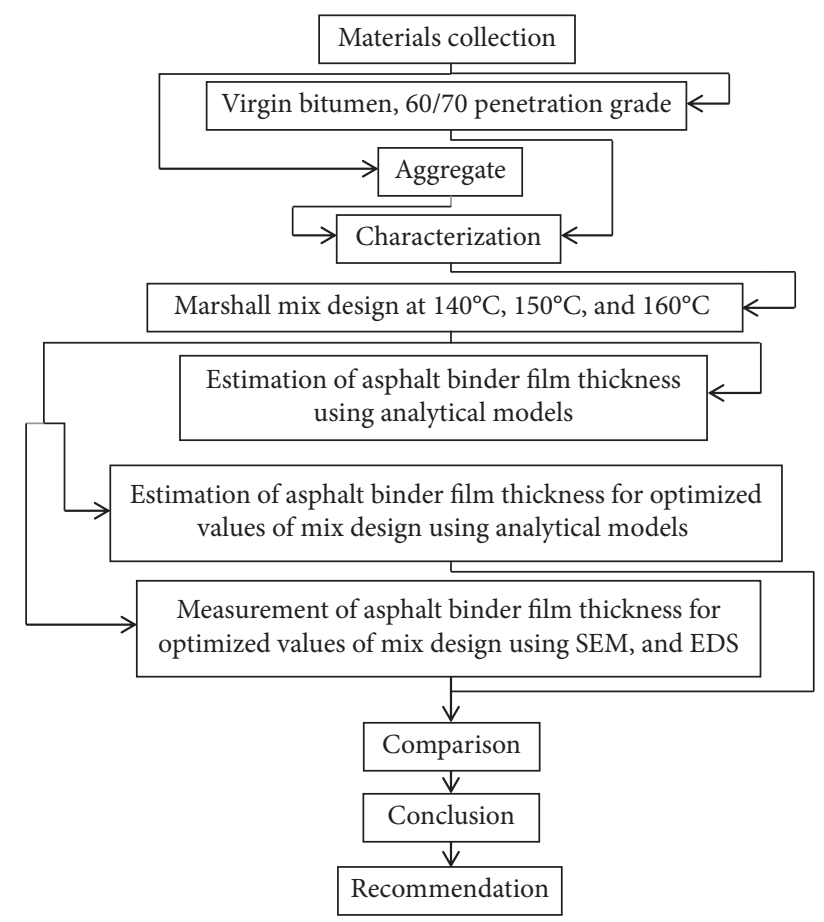

FIGURE 1: Flow chart showing research methodology. according to the Marshall procedure described in ASTM D1559 [42]. The Marshall specimens were prepared by filling Marshall mold, having a diameter of 4 inches and thickness of 2.5 inches, and compacted with 75 blows of the standard Marshall hammer for heavy traffic on each side of the sample. In the first phase, 45 asphalt samples were prepared where a number of three (03) asphalt samples were to be examined at each binder content of $3.5 \%, 4 \%, 4.5 \%, 5 \%$, and $5.5 \%$ by weight of Marshall sample at each mixing temperature of $140^{\circ} \mathrm{C}, 150^{\circ} \mathrm{C}$, and $160^{\circ} \mathrm{C}$. The samples were kept in water at $60^{\circ} \mathrm{C}$ for one hour before testing. Marshall Tester was then used for finding stability and flow values. In the second phase, the Marshall mix design volumetrics were further used to estimate average asphalt binder film thickness for each combination of asphalt sample using aforementioned analytical models and results which are presented in Table 7 . In the third phase, optimum binder contents (OBC) were determined for asphalt mixtures prepared at each mixing temperature of $140^{\circ} \mathrm{C}, 150^{\circ} \mathrm{C}$, and $160^{\circ} \mathrm{C}$. The Marshall specimens were prepared at each $\mathrm{OBC}$ with the corresponding temperature of $140^{\circ} \mathrm{C}$ to $160^{\circ} \mathrm{C}$. The Marshall specimens were again tested and the data were used to determine asphalt binder film thickness for the optimized values of binder contents at various temperatures and presented in Table 7. Asphalt binder film thickness in asphalt mixtures prepared at optimized binder contents was also verified by image analysis using SEM and EDS. Asphalt binder film thicknesses measured by SEM are presented in Table 8.

The asphalt mixtures prepared at the specified binder content and mixing temperature, as shown in Table 7, were tested and stability, flow, VMA, VFA, and VTM values were recorded as per ASTM D1559 [42]. The stability of the HMA samples met the minimum criteria of $8.0 \mathrm{KN}$ with corresponding flow at all mixing temperatures. The bulk and theoretical specific gravities were determined as per ASTM D1559 [42] and ASTM D2041 [43], ranging from 2.309 to 


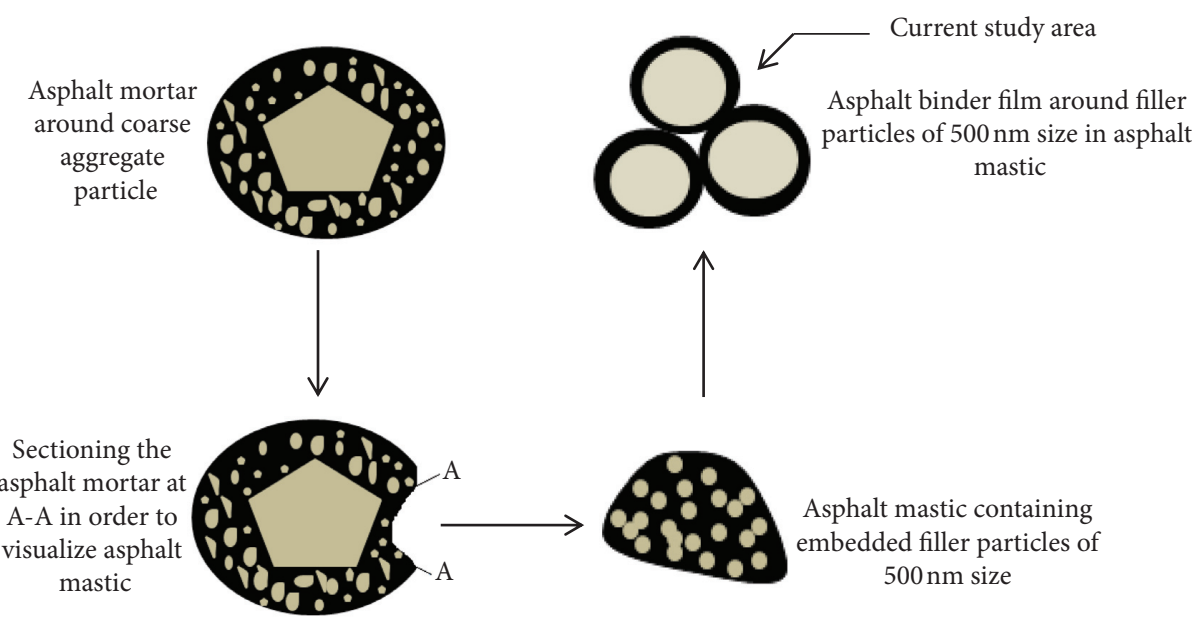

FIGURE 2: Flow chart showing research area.

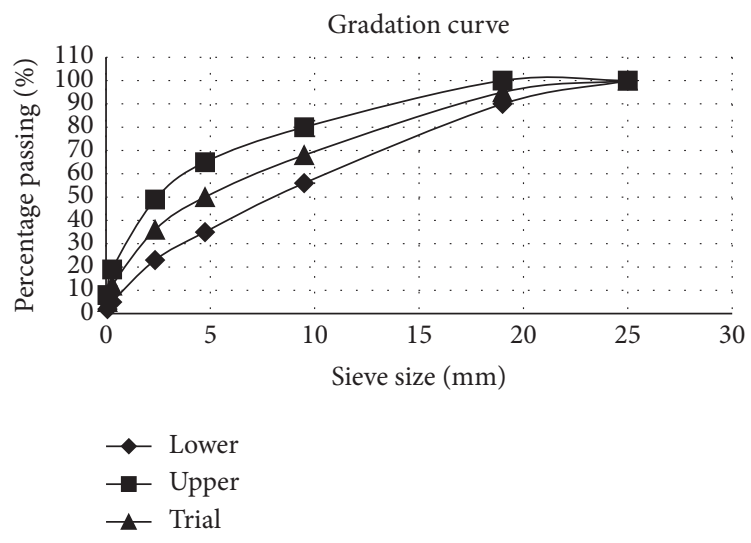

Figure 3: Aggregate gradation.

2.350 and 2.411 to 2.522 , respectively. The VMA, VFA, and VTM mostly met the criteria of $14 \%$ (min.), $65 \%$ to $75 \%$, and $3 \%$ to $5 \%$, respectively. The $P_{b a}$ values were determined as per ASTM D2041 [43] with an overall range of $0.007 \%$ to $5.1 \%$.

4.2. Estimating the Surface Area of Aggregates. The surface area for each sieve is usually estimated by multiplying an appropriate surface area factor by the percentage passing through a particular sieve. Summing all the calculated areas equals the total surface area (SA) in $\left(\mathrm{m}^{2} / \mathrm{kg}\right)$ for the asphalt mixture considered. The total surface area of the aggregate blend used in the current study as per Asphalt Institute gradation, Class-A, for the asphalt wearing course, is calculated and presented in Table 9.

Optimum bitumen contents of $4.36 \%, 4.23 \%$, and $4.12 \%$ were concluded for mix design at $140^{\circ} \mathrm{C}, 150^{\circ} \mathrm{C}$, and $160^{\circ} \mathrm{C}$, respectively. The variation in estimated asphalt binder film thickness, using aforementioned analytical models, is presented in Table 7.

The relationship between model-based film thickness and VFA calculated at various binder contents and mixing temperatures is plotted and presented in Figure 4.
It may be noted from Figure 4 the relationship between the asphalt binder film thickness and VFA is described by a linear function with a determination coefficient $\left(R^{2}\right)$ of 0.58 , 0.53 , and 0.17 respectively, showing that the relationship is not highly significant. The film thickness equations, despite the fact that $P_{b e}$ is a volumetric phase representing VFA in the mixture, show that there is a nonlinearity in the relationship between $F T_{b}$ and $P_{b e}$. It may also be noted from Figure 4 the percentage VFA for the corresponding film thickness and temperature vary between $67.1 \%$ and $78.71 \%$. However, the specification limits support any value of film thickness between $65 \%$ and $75 \%$.

Rut resistance of asphalt mixtures prepared at optimum bitumen content of $4.36 \%, 4.23 \%$, and $4.12 \%$ and mixing temperature of $140^{\circ} \mathrm{C}, 150^{\circ} \mathrm{C}$, and $160^{\circ} \mathrm{C}$, respectively, was also determined and is presented in Figure 5.

Figure 4 shows that the rut resistance of asphalt mixture prepared at binder content of $4.12 \%$ and mixing temperature of $160^{\circ} \mathrm{C}$ is higher as compared to the mixture prepared at $140^{\circ} \mathrm{C}$ and $150^{\circ} \mathrm{C}$.

4.3. Image Analysis Using SEM and EDS. SEM-JEOL JSM IT 100 available with secondary electron detector (SED), backscattered electron detector (BSED), and energy dispersive X-ray spectroscopy (EDS) features was used in this study at magnifications between $\times 200$ and $\times 30,000$, as shown in Figure 6(a). Due to high experimental cost, the current study is limited to SEM to capture high resolution images in order to detect asphalt binder film and EDS is only used for elemental composition of asphalt binder film already detected by SEM in compacted asphalt mixtures. The sample preparation started by cutting Marshall specimens with a diamond saw to reveal the internal structure of the material. The sample was further cut and obtained $8 \mathrm{~mm} \times 8 \mathrm{~mm} \times 6 \mathrm{~mm}$ and $12 \mathrm{~mm} \times 8 \mathrm{~mm} \times 6 \mathrm{~mm}$ specimens, as shown in Figures 7(b) and 7(c). A spot of interest was then marked in the specified specimen, and the sample was then coated with gold ( $4 \mathrm{~nm}$ thick) thin film by Gold Sputter Coater in order to make the surface of the sample conductive as shown in Figures 6(b) and 6(c). This metal-coated layer is 
TABLE 7: Estimated asphalt binder film thicknesses using analytical models.

\begin{tabular}{|c|c|c|c|c|c|c|c|c|c|}
\hline \multirow[t]{2}{*}{$\begin{array}{l}\text { Analytical models to estimate asphalt binder film } \\
\text { thickness }\end{array}$} & \multirow[t]{2}{*}{$\begin{array}{l}\text { Mixing temperature } \\
\qquad\left({ }^{\circ} \mathrm{C}\right)\end{array}$} & \multicolumn{5}{|c|}{$\begin{array}{l}\text { Asphalt binder film thickness } \\
\qquad(\mu \mathrm{m})\end{array}$} & \multicolumn{3}{|c|}{$\begin{array}{l}\text { Asphalt binder film } \\
\text { thickness at } \\
\text { optimized bitumen } \\
\text { content }\end{array}$} \\
\hline & & $3.5 \%$ & $4 \%$ & $4.5 \%$ & $5 \%$ & $5.5 \%$ & $4.36 \%$ & $4.23 \%$ & $4.12 \%$ \\
\hline \multirow{3}{*}{$F T_{b}=10^{5} P_{b e} / P_{s} \times G_{b} \sum\left(\mathrm{SAF}_{i} \times P_{i}\right)$} & 140 & 12.82 & 12.93 & 13.04 & 13.16 & 13.29 & 12.46 & \multirow{3}{*}{12.32} & \\
\hline & 150 & 11.96 & 12.50 & 12.61 & 12.73 & 12.02 & & & \\
\hline & 160 & 11.11 & 11.22 & 11.34 & 11.05 & 10.36 & & & 11.35 \\
\hline \multirow{3}{*}{$F_{b e}=981 \times P_{b e} /\left(\operatorname{SST} \times\left(100-P_{b}\right)\right)$} & 140 & 12.57 & 12.64 & 12.71 & 12.78 & 12.85 & 12.39 & \multirow{3}{*}{12.26} & \\
\hline & 150 & 11.72 & 12.22 & 12.29 & 12.36 & 11.59 & & & \\
\hline & 160 & 10.88 & 10.96 & 11.03 & 10.70 & 9.96 & & & 11.29 \\
\hline \multirow{3}{*}{$\mathrm{DA}=P_{b e} \times 1000 /\left(100-P_{b}\right) \times \gamma_{b} \times \mathrm{SA}$} & 140 & 12.69 & 12.76 & 12.83 & 12.90 & 12.97 & 12.27 & \multirow{3}{*}{12.13} & \\
\hline & 150 & 11.83 & 12.33 & 12.40 & 12.47 & 11.70 & & & \\
\hline & 160 & 10.98 & 11.06 & 11.13 & 10.79 & 10.06 & & & 11.18 \\
\hline \multirow{3}{*}{$T_{F}=(b / 100-b) \times\left(1 / \rho_{b}\right) \times(1 / \mathrm{SA})$} & 140 & 8.60 & 9.88 & 11.20 & 12.50 & 13.80 & 10.80 & \multirow{3}{*}{10.50} & \\
\hline & 150 & 8.60 & 9.88 & 11.20 & 12.50 & 13.80 & & & \\
\hline & 160 & 8.60 & 9.88 & 11.20 & 12.50 & 13.80 & & & 9.88 \\
\hline \multirow{3}{*}{$T_{f}=\left[W_{b} /(\mathrm{SA} \times 1000)\right] \times G_{b}$} & 140 & 8.92 & 10.30 & 11.60 & 13.00 & 14.30 & 11.20 & \multirow{3}{*}{11.0} & \\
\hline & 150 & 8.92 & 10.30 & 11.60 & 13.00 & 14.30 & & & \\
\hline & 160 & 8.92 & 10.30 & 11.60 & 13.00 & 14.30 & & & 10.81 \\
\hline \multirow{3}{*}{$F=10^{6} P_{b e} /\left(100-P_{b}\right) \times(1 / \mathrm{SA}) \times\left(1 / \rho_{b}\right)$} & 140 & 12.60 & 12.71 & 12.83 & 12.94 & 13.07 & 12.25 & \multirow{3}{*}{12.11} & \\
\hline & 150 & 11.76 & 12.29 & 12.40 & 12.52 & 11.82 & & & \\
\hline & 160 & 10.92 & 11.04 & 11.15 & 10.87 & 10.19 & & & 11.16 \\
\hline
\end{tabular}

TABLE 8: Microscopically measured film thicknesses at optimized binder content of $4.36 \%$ to $4.12 \%$ and temperature $140^{\circ} \mathrm{C}$ to $160^{\circ} \mathrm{C}$.

Bitumen content (\%) Temperature $\left({ }^{\circ} \mathrm{C}\right)$ Film thicknesses by SEM $(\mu \mathrm{m})$ Minimum film thickness $(\mu \mathrm{m})$ Maximum film thickness $(\mu \mathrm{m})$

\begin{tabular}{|c|c|c|c|c|}
\hline \multirow{6}{*}{4.36} & \multirow{6}{*}{140} & 0.5 & \multirow{6}{*}{0.5} & \multirow{6}{*}{2.4} \\
\hline & & 0.8 & & \\
\hline & & 0.9 & & \\
\hline & & 1 & & \\
\hline & & 1.3 & & \\
\hline & & 2.4 & & \\
\hline \multirow{7}{*}{4.23} & \multirow{7}{*}{150} & 0.5 & \multirow{7}{*}{0.5} & \multirow{7}{*}{2.35} \\
\hline & & 1 & & \\
\hline & & 1.2 & & \\
\hline & & 1.3 & & \\
\hline & & 1.6 & & \\
\hline & & 1.7 & & \\
\hline & & 2.35 & & \\
\hline \multirow{6}{*}{4.12} & \multirow{6}{*}{160} & 0.5 & \multirow{6}{*}{0.5} & \multirow{6}{*}{2.4} \\
\hline & & 1.1 & & \\
\hline & & 1.3 & & \\
\hline & & 1.7 & & \\
\hline & & 1.8 & & \\
\hline & & 2.4 & & \\
\hline
\end{tabular}

TABLE 9: Surface area calculation according to AI gradation.

\begin{tabular}{lcccccc}
\hline Sieve size $(\mathrm{mm})$ & 25 & 19 & 9.5 & 4.75 & 2.36 & 0.3 \\
Selected blend $(\%$ passing) & 100 & 95 & 68 & 50 & 36 & 0.075 \\
Surface area factors $\left(\mathrm{m}^{2} / \mathrm{kg}\right)$ & 0.41 & 0.41 & 0.41 & 0.41 & 0.82 & 6.14 \\
Surface area $\left(\mathrm{m}^{2} / \mathrm{kg}\right)$ & 0.410 & 0.410 & 0.410 & 0.205 & 0.295 & 0.736 \\
Total surface area $\left(\mathrm{m}^{2} / \mathrm{kg}\right)$ & & & & 4.104 & & \\
\hline
\end{tabular}

so thin that all the microtexture at the surface of HMA is preserved and observed during the SEM process, as shown in Figure $7(\mathrm{c})$. In order to detect and measure thickness of asphalt binder film by SEM and EDS, three asphalt samples were prepared and analyzed at each optimized binder content of $4.36 \%, 4.23 \%$, and $4.12 \%$ by weight of Marshall 


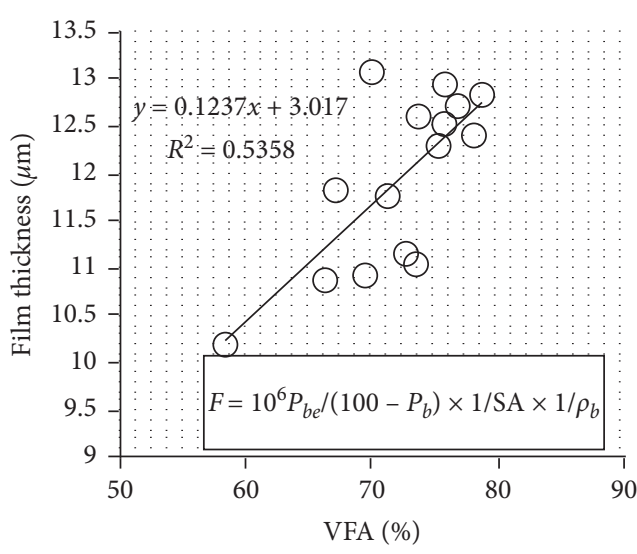

(a)

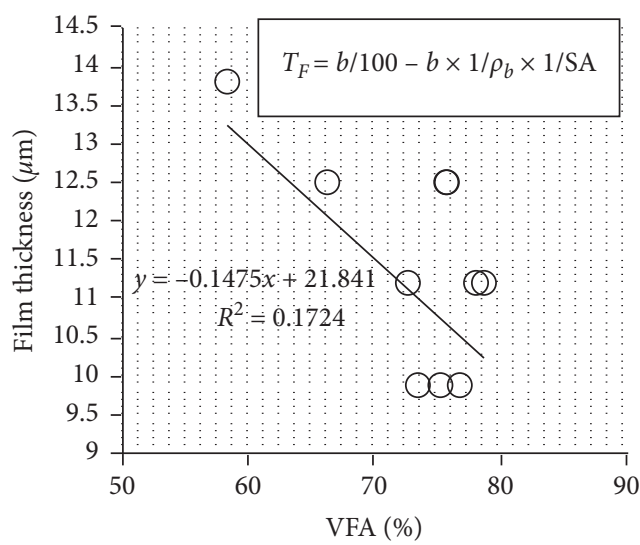

(c)

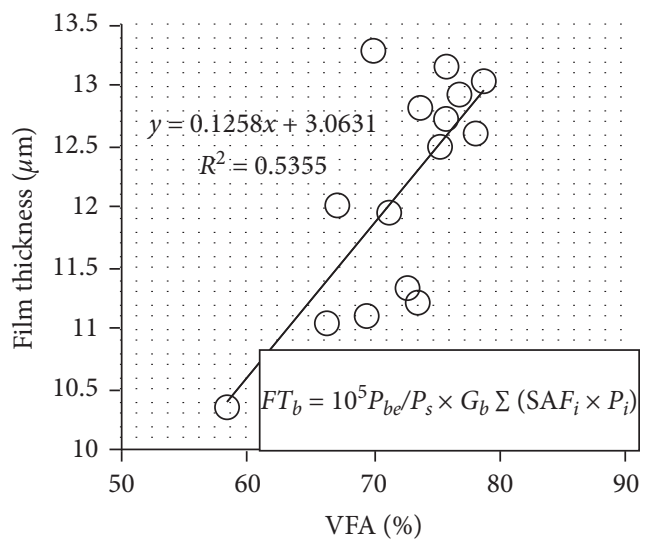

(e)

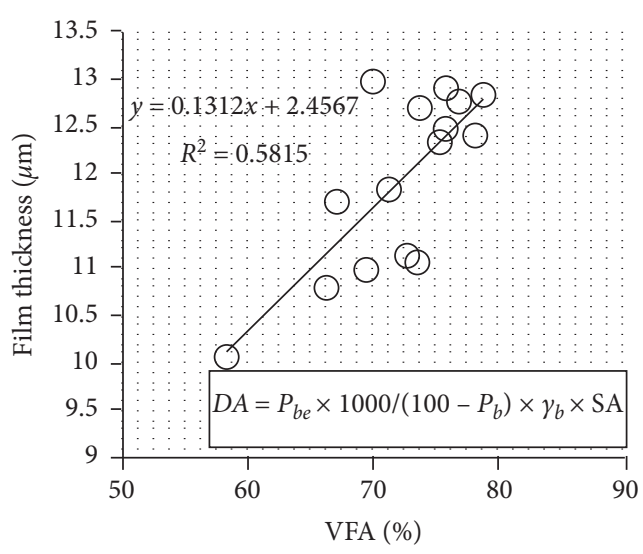

(b)

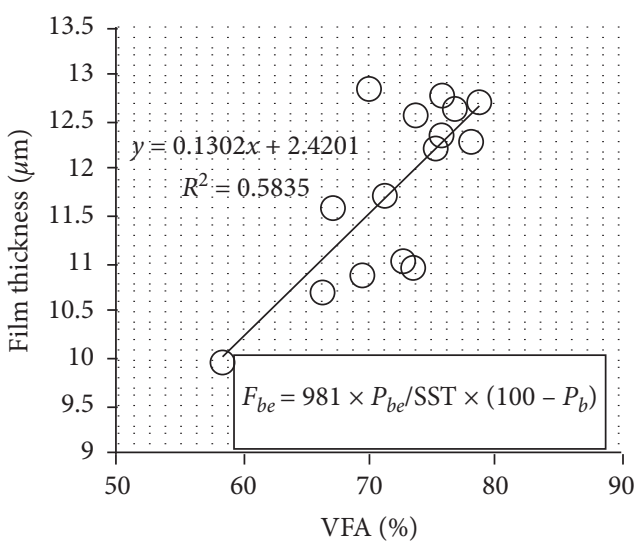

(d)

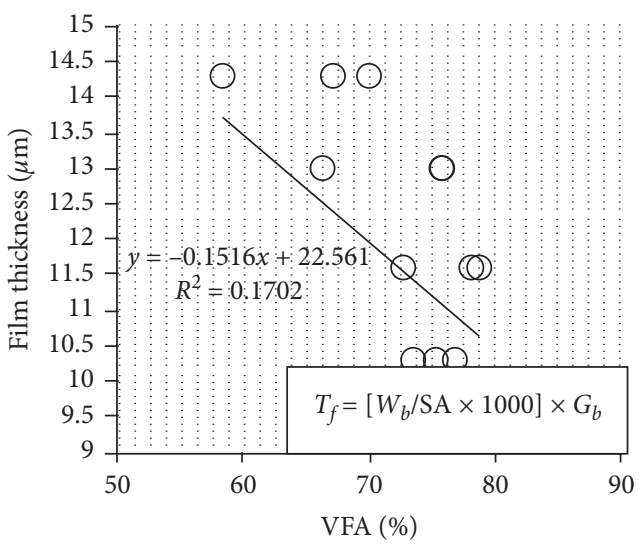

(f)

FIGURE 4: Relation between film thickness and VFA.

sample at each mixing temperature of $140^{\circ} \mathrm{C}, 150^{\circ} \mathrm{C}$, and $160^{\circ} \mathrm{C}$. The samples were thoroughly examined through image analysis using SEM. The asphalt mastic and asphalt binder film thickness were measured at various spots of the asphalt samples.

4.4. Development in Asphalt Binder Film Thickness Using SEM and EDS. The word development refers to the improvement in the technology and procedures to find out the asphalt binder film thickness. In order to detect and measure asphalt binder film thickness, high resolution images were taken by SEM and EDS of the gold coated asphalt specimens extracted from Marshall samples prepared under different optimized binder contents and mixing temperatures, as presented in Figures 6-8. The SEM images revealed that the asphalt binder film thicknesses range from $0.5 \mu \mathrm{m}$ to $2.4 \mu \mathrm{m}$ with no relation to binder content and mixing temperature, as presented in Table 8 .

A comparison between the analytically estimated and microscopically measured film thicknesses under all 


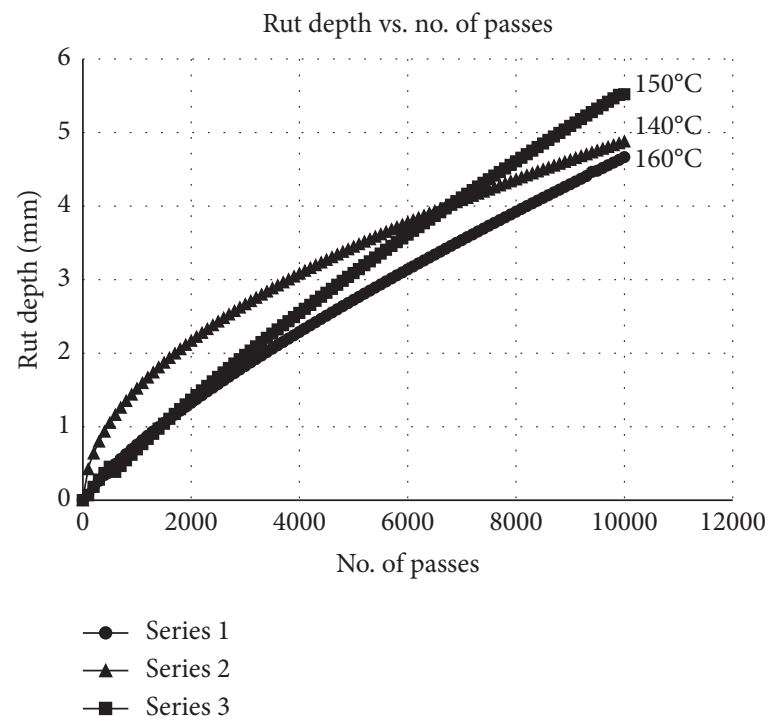

FIgURE 5: Relation between rut depth and no. of passes.

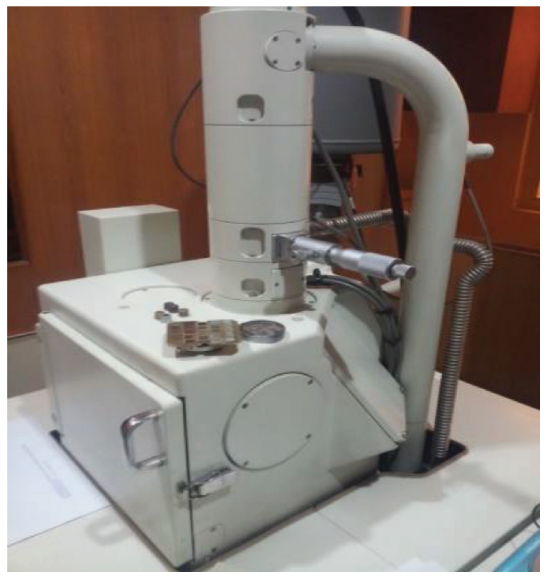

(a)

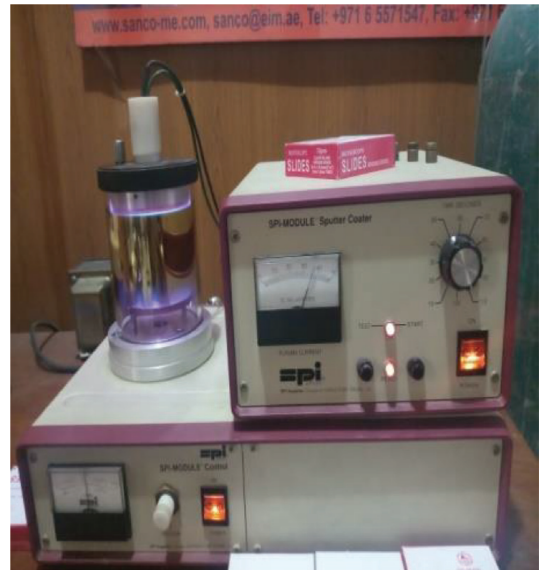

(b)

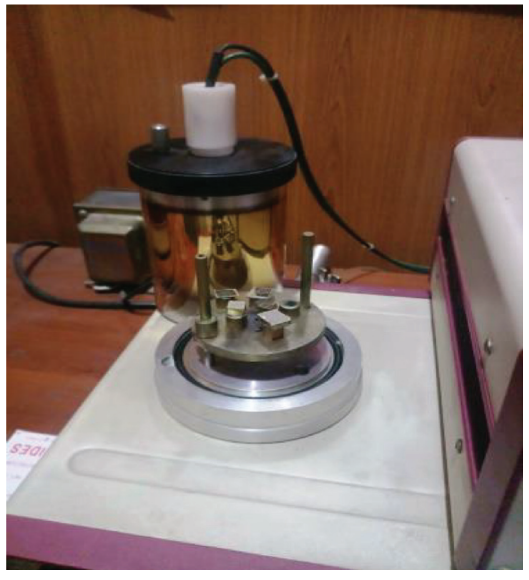

(c)

FIGURE 6: SEM set-up: (a) SEM-JEOL JSM IT100, (b) sputter coater, and (c) asphalt specimen coating.

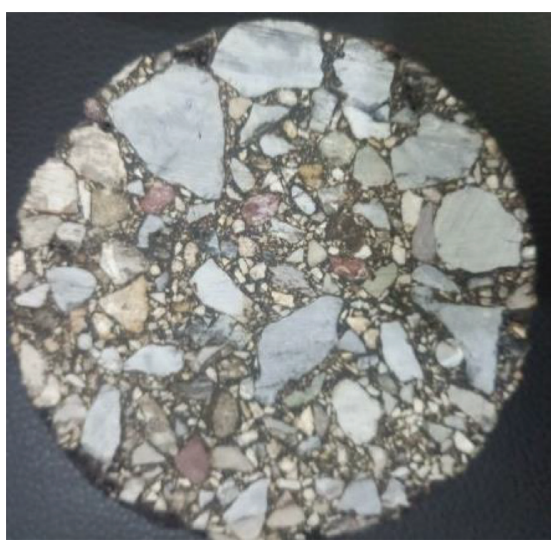

(a)

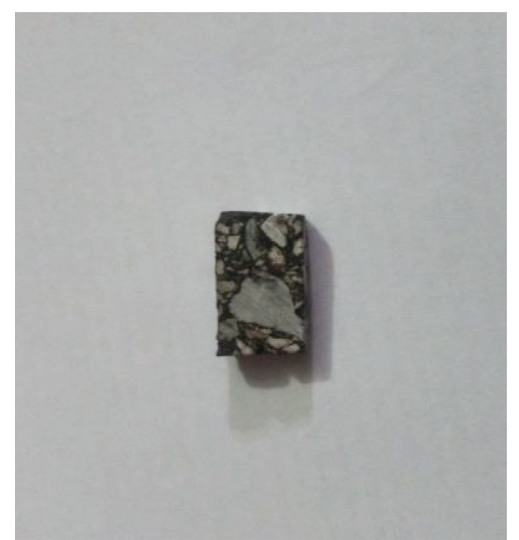

(b)

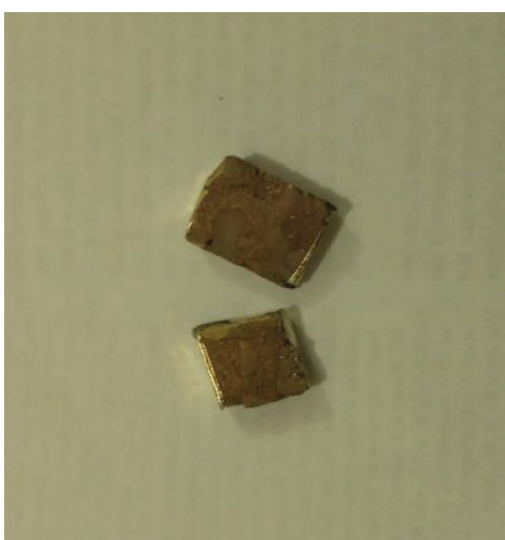

(c)

FIgURE 7: Sample preparation: (a) Marshall specimen, (b) specimen without coating, and (c) gold coated specimens. 


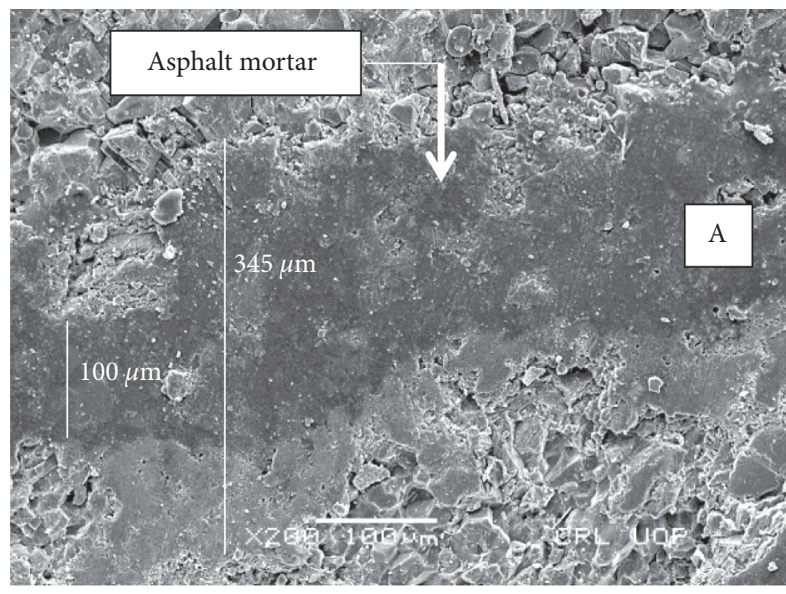

(a)

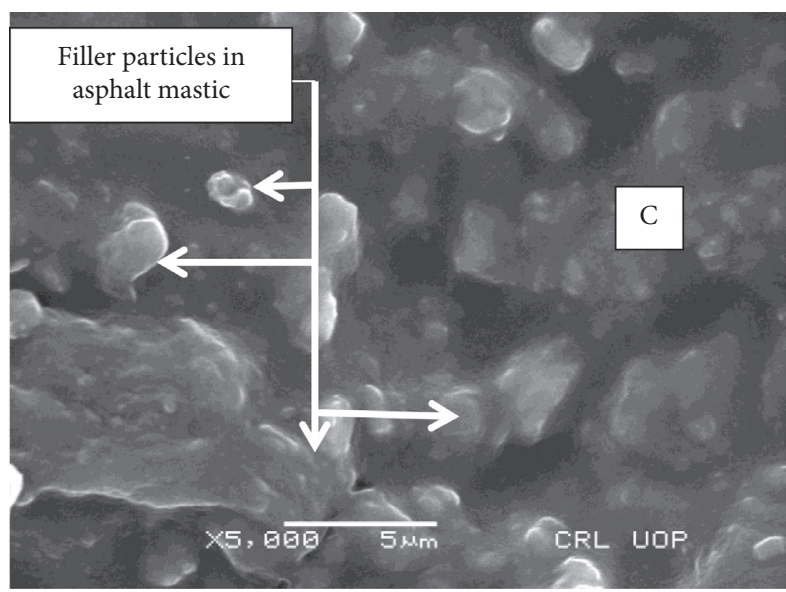

(c)

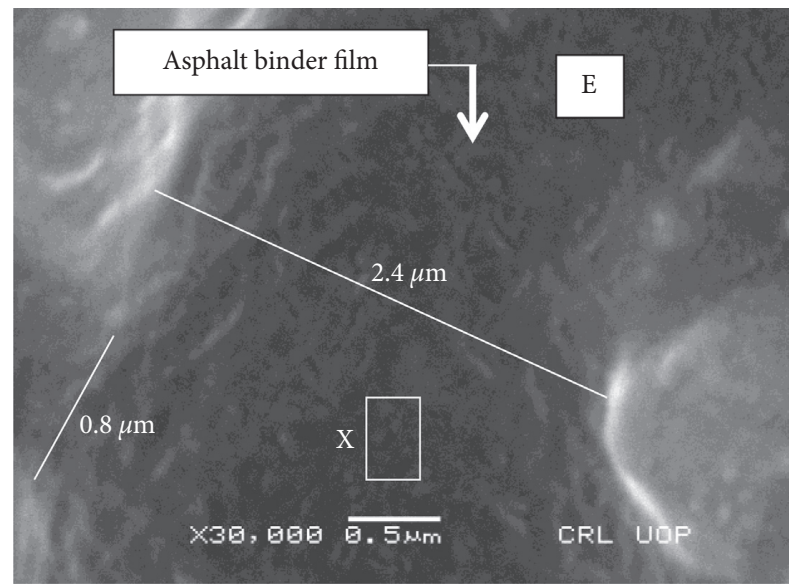

(e)

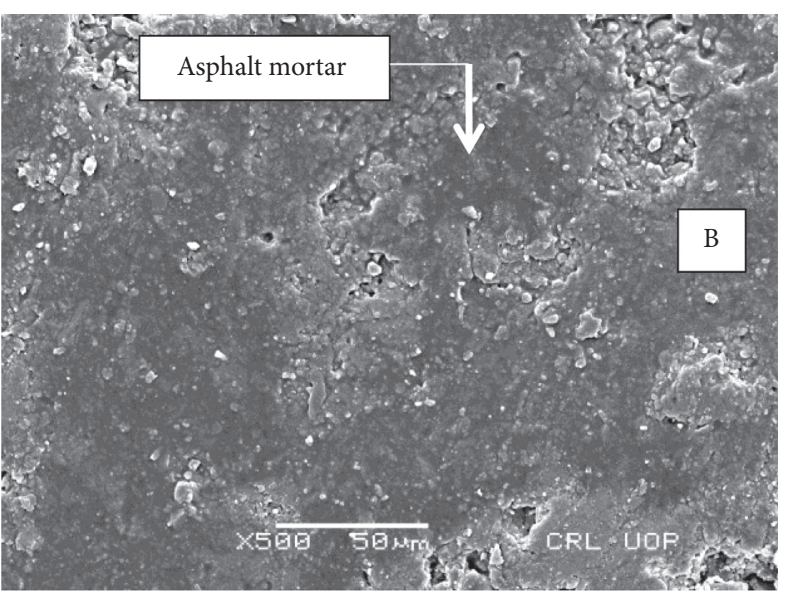

(b)

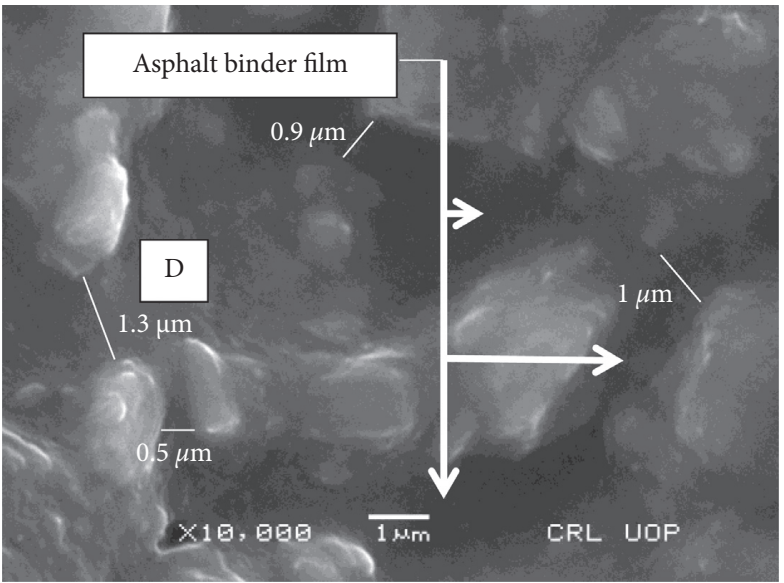

(d)

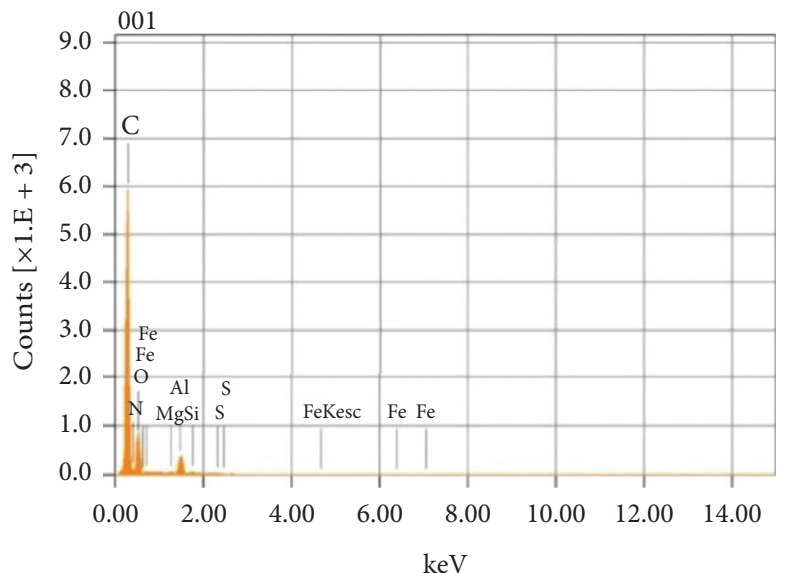

$\begin{array}{lcccccc}\text { Formula } & \text { Mass\% } & \text { Atom\% } & \text { Sigma } & \text { Net } & \text { K ratio } & \text { Line } \\ \mathrm{C} & 66.19 & 72.64 & 0.03 & 145079 & 0.0182991 & \mathrm{~K} \\ \mathrm{~N}^{*} & 1.77 & 1.66 & 0.02 & 4380 & 0.0074943 & \mathrm{~K} \\ \mathrm{O} & 30.02 & 24.74 & 0.15 & 20624 & 0.0118878 & \mathrm{~K} \\ \mathrm{Mg} & 0.21 & 0.12 & 0.01 & 1599 & 0.0003599 & \mathrm{~K} \\ \mathrm{Al} & 1.42 & 0.69 & 0.02 & 13367 & 0.0024045 & \mathrm{~K} \\ \mathrm{Si} & 0.18 & 0.08 & 0.01 & 1777 & 0.0003088 & \mathrm{~K} \\ \mathrm{~S}^{*} & 0.09 & 0.04 & 0.01 & 933 & 0.0001915 & \mathrm{~K} \\ \mathrm{Fe}^{*} & 0.12 & 0.03 & 0.01 & 402 & 0.0002390 & \mathrm{~K} \\ \text { Total } & 100.00 & 100.00 & & & & \mathrm{~K}\end{array}$

(f)

FIGURE 8: SEM images of HMA at $140^{\circ} \mathrm{C}$ and optimized binder content of $4.36 \%$ : (a) asphalt mortar at magnification $\times 200$ and bar scale $100 \mu \mathrm{m}$. (b) Asphalt mortar at magnification $\times 500$ and bar scale $50 \mu \mathrm{m}$. (c) Filler particles at magnification $\times 5000$ and bar scale $5 \mu \mathrm{m}$. (d) Asphalt binder film at magnification $\times 10,000$ and bar scale $1 \mu \mathrm{m}$. (e) Asphalt binder film at magnification $\times 30,000$ and bar scale $0.5 \mu \mathrm{m}$.

(f) Elemental composition of asphalt binder film at point $X$ in image (e) by EDS. 
conditions of temperature and binder contents is given in Table 10. The analytical models used in the current study overestimate the asphalt binder film thickness as they do not agree to the microscopically measured values of asphalt binder film thickness. Therefore, a conversion factor is suggested to be used for analytical models so that estimated values of film thickness can be compared to the measured values of asphalt binder film thickness, as presented in Table 10 .

\section{Results and Discussion}

5.1. Asphalt Binder Film Thickness Based on Analytical Models. Total 45 asphalt samples were prepared at a binder content of $3.5 \%, 4 \%, 4.5 \%, 5 \%$, and $5.5 \%$ by weight of Marshall specimen, with a mixing temperature ranging from $140^{\circ} \mathrm{C}$ to $160^{\circ} \mathrm{C}$, and tested as per the laid down procedures in ASTM D1559. The results were further used to theoretically estimate asphalt binder film thickness for the aforementioned conditions using analytical models provided in Table 3, and the results of film thicknesses are recorded in Table 7.

The asphalt binder film thicknesses at $140^{\circ} \mathrm{C}$ showed an increasing trend with respect to rise in binder content at low temperature. This rise in film thickness is most probably because of inability of the aggregates to move towards voids due to ineffective compaction at low temperature. Therefore, most of the bitumen remains as a thicker coat around the aggregate thereby increasing film thickness. Most of the models at $150^{\circ} \mathrm{C}$ and $160^{\circ} \mathrm{C}$ showed an increasing trend in film thickness up to $4.5 \%$ bitumen content. But onward $4.5 \%$ bitumen content, the film thickness showed a decreasing trend.

However, the overall asphalt film thicknesses showed a decreasing trend with respect to rise in mixing temperature. The decreasing trend in film thickness with respect to rise in temperature is most probably because of thinner coat of bitumen on the aggregate surface due to effective compaction at higher temperature. The asphalt binder film thickness calculated on the basis of analytical model presented by Read and Whiteoak and Zaniewski et al. showed an increasing trend with respect to rise in binder content but showed no dependency with respect to rise in temperature as the values of film thicknesses with respect to rise in temperature are constant. This is because the stated models are based on the density of binder and surface area of aggregates as major parameters rather than temperature-oriented properties such as bulk and theoretical specific gravities of the asphalt mixture. The overall asphalt film thickness, calculated on the basis of asphalt binder by total mix ranging from $3.5 \%$ to $5.5 \%$, ranged from $8 \mu \mathrm{m}$ to $14.30 \mu \mathrm{m}$. However, the asphalt binder film thickness, calculated on the basis of optimized binder content ranging from $4.36 \%$ to $4.12 \%$ at a mixing temperature of $140^{\circ} \mathrm{C}$ to $160^{\circ} \mathrm{C}$, ranged from $9 \mu \mathrm{m}$ to $13 \mu \mathrm{m}$.

It is clear from the above discussion that the analytical film thickness models presented by Al-Khateeb, Superpave series no. 2 (SP-2), Lv. Debao, and Road Note 19 TRL Ltd., are closely related as the film thickness values and their trend with respect to rise in binder content and temperature are almost comparable. It is also clear that the film thickness models presented by Read and Whiteoak and Zaniewski et al. are also closely related as the values and their pattern with respect to binder content and temperature are almost comparable. But still, if we compare the values of film thickness provided in Table 7 , it is noted that the models provided in Table 3 did not provide such a value of film thickness which may be validated by other models provided in the same Table 4. Therefore, an accurate and validated value for film thickness was difficult to get as the models do not agree on a single value or a particular range of film thicknesses, thus showing uncertainty in conventional procedure to estimate asphalt binder film thickness.

\subsection{Analysis of Asphalt Samples Based on SEM and EDS.} SEM images were taken from low to high magnification in order to investigate different features on the surface of the asphalt specimens, extracted from asphalt samples. These asphalt samples were prepared at optimized binder content of $4.36 \%, 4.23 \%$, and $4.12 \%$ and mixing temperature of $140^{\circ} \mathrm{C}, 150^{\circ} \mathrm{C}$, and $160^{\circ} \mathrm{C}$, respectively. The asphalt samples at the aforementioned conditions were analyzed experimentally by SEM and EDS, and entities as small as $500 \mathrm{~nm}$ $(0.5 \mu \mathrm{m})$ were detected in the images provided in Figures 8-10. The results from the images lead to the following observations:

The SEM image of the asphalt sample at $140^{\circ} \mathrm{C}$ and magnification of $\times 200$ with a bar scale of $100 \mu \mathrm{m}$ shows the asphalt mortar, a mixture of binder, fine aggregate, and mineral filler, ranging from $100 \mu \mathrm{m}$ to $345 \mu \mathrm{m}$, and used to grip coarser particles in asphalt mixture as, shown in Figure 8(a), point A. No voids at the aforementioned magnification have been observed in the asphalt mortar because of the mobility of mortar during production and compaction during placement, but voids can be observed at the interface between mortar and coarser particles, as shown in Figure 8(a). The voids at the interface may originate weak zone and may be open to failure. The SEM image taken at magnification of $\times 250$ with a bar scale of $100 \mu \mathrm{m}$ reveals that asphalt mortar ranges up to $260 \mu \mathrm{m}$ for the asphalt samples prepared at $150^{\circ} \mathrm{C}$. Again, no voids at the aforementioned magnification have been observed in the asphalt mastic, as shown in Figure 9(a), point A. Similarly, the SEM image taken at magnification of $\times 200$ with a bar scale of $100 \mu \mathrm{m}$ of the asphalt sample prepared at $160^{\circ} \mathrm{C}$ also shows the asphalt mortar ranges from up to $365 \mu \mathrm{m}$ with no voids observed in mastic, as shown in Figure 10(a), point A. From the SEM images of the asphalt samples prepared at $140^{\circ} \mathrm{C}, 150^{\circ} \mathrm{C}$, and $160^{\circ} \mathrm{C}$, it has been observed that the mortar ranges from $100 \mu \mathrm{m}$ to $365 \mu \mathrm{m}$, as shown in Figures 8(a), 9(a), and 10(a), point $\mathrm{A}$. The asphalt mastic, a two-phase system containing bitumen and filler blended together, was observed when the images were taken at magnifications of $\times 500$ and $\times 300$ with a bar scale of $50 \mu \mathrm{m}$, as shown in Figures 8(b) and 9(b). The SEM image of the asphalt samples prepared at $160^{\circ} \mathrm{C}$, at magnifying power of $\times 2500$ with a bar scale of $10 \mu \mathrm{m}$, shows various shapes of the filler particles such as flaky, elongated, 
TABle 10: Comparison of film thicknesses and suggested average conversion factors based on SEM measurement.

\begin{tabular}{|c|c|c|c|}
\hline $\begin{array}{l}\text { SEM and analytical models to estimate asphalt binder film } \\
\text { thickness }(\mu \mathrm{m})\end{array}$ & $\begin{array}{l}\text { Minimum film } \\
\text { thickness }(\mu \mathrm{m})\end{array}$ & $\begin{array}{l}\text { Maximum film } \\
\text { thickness }(\mu \mathrm{m})\end{array}$ & $\begin{array}{l}\text { Suggested average conversion } \\
\text { factor as per SEM study }\end{array}$ \\
\hline SEM & 0.5 & 2.4 & \multirow{7}{*}{0.120} \\
\hline$F T_{b}=10^{5} P_{b e} / P_{s} \times G_{b} \sum \mathrm{SAF}_{i} \times P_{i}$ & 11.35 & 12.46 & \\
\hline$F_{b e}=981 \times P_{b e} / \mathrm{SST} \times\left(100-P_{b}\right)$ & 11.29 & 12.39 & \\
\hline $\mathrm{DA}=P_{b e} \times 1000 /\left(100-P_{b}\right) \times \gamma_{b} \times \mathrm{SA}$ & 11.18 & 12.27 & \\
\hline$T_{F}=(b / 100-b) \times\left(1 / \rho_{b}\right) \times(1 / S A)$ & 9.88 & 10.80 & \\
\hline$T_{f}=\left[W_{b} / \mathrm{SA} \times 1000\right] \times G_{b}$ & 10.81 & 11.20 & \\
\hline$F=10^{6} P_{b e} /\left(100-P_{b}\right) \times(1 / \mathrm{SA}) \times\left(1 / \rho_{b}\right)$ & 11.16 & 12.25 & \\
\hline
\end{tabular}

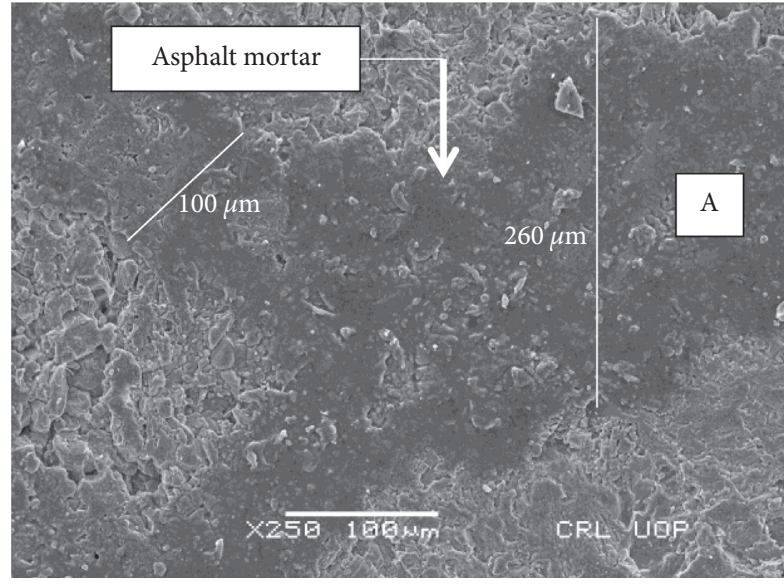

(a)

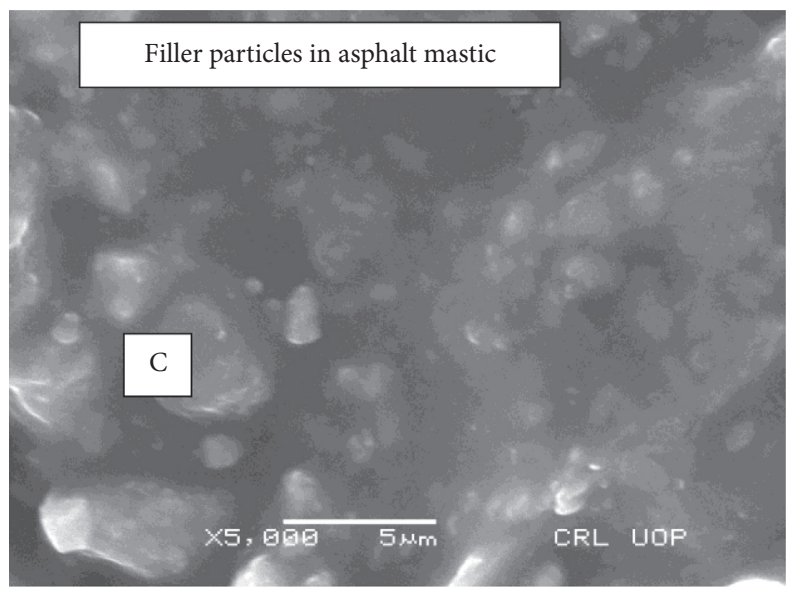

(c)

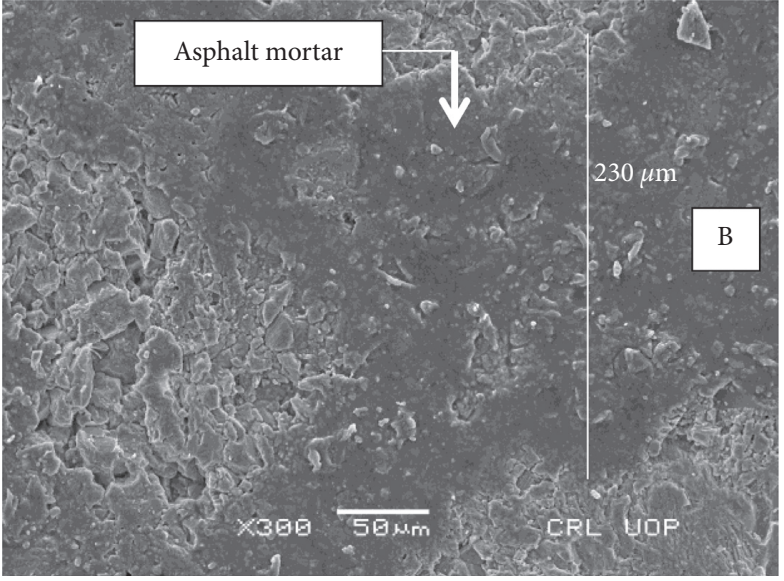

(b)

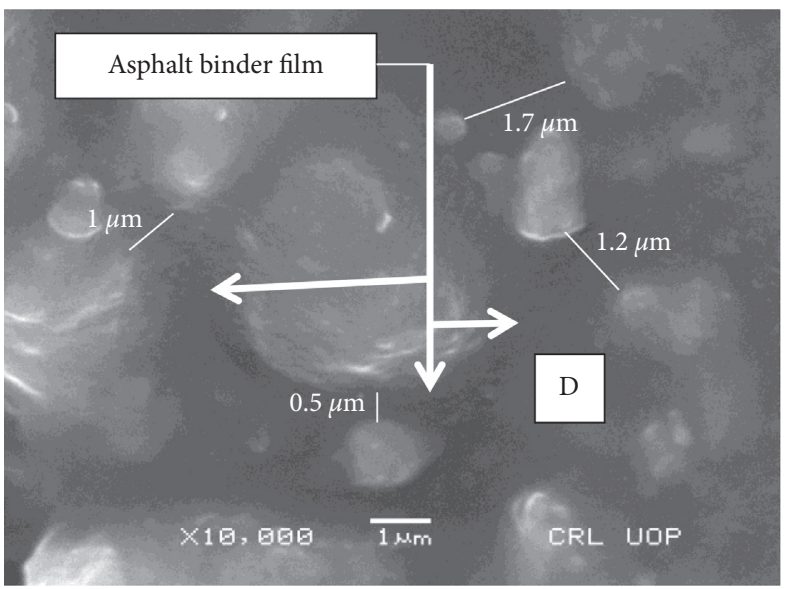

(d)

FIGURE 9: Continued. 

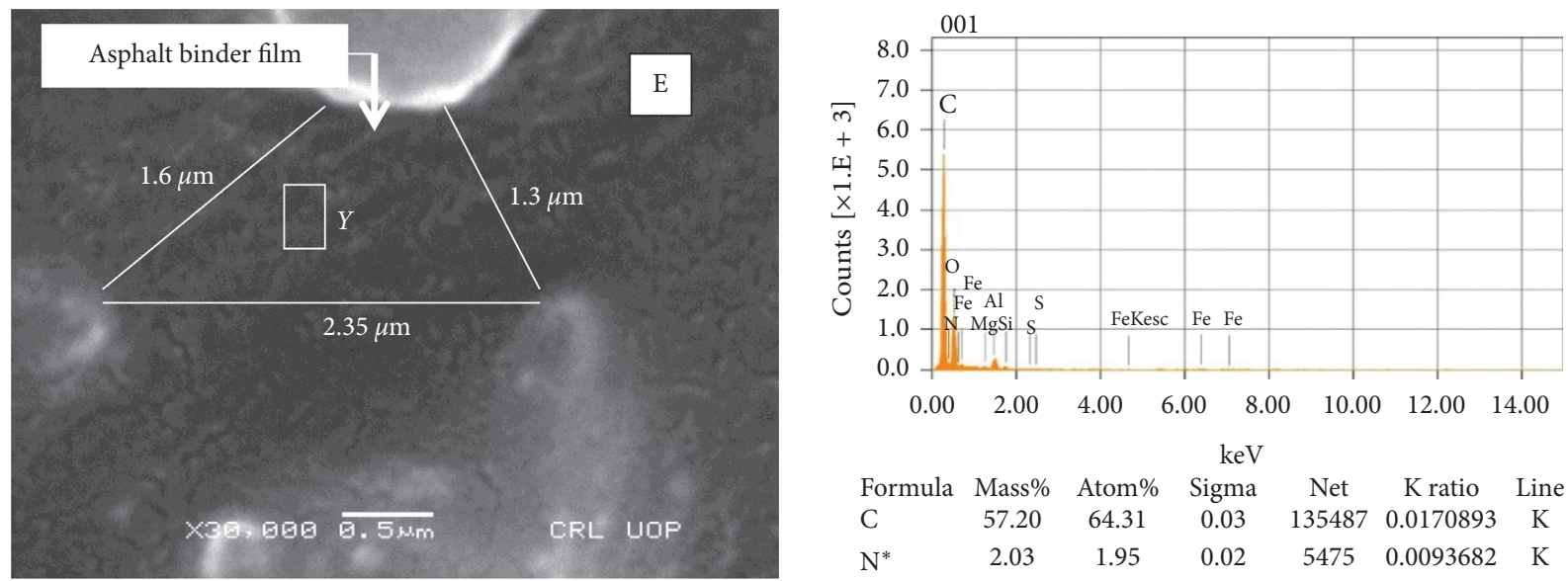

$\begin{array}{lcccccc}\text { Formula } & \text { Mass } \% & \text { Atom\% } & \text { Sigma } & \text { Net } & \text { K ratio } & \text { Line } \\ \mathrm{C} & 57.20 & 64.31 & 0.03 & 135487 & 0.0170893 & \mathrm{~K} \\ \mathrm{~N}^{*} & 2.03 & 1.95 & 0.02 & 5475 & 0.0093682 & \mathrm{~K} \\ \mathrm{O} & 39.11 & 33.01 & 0.15 & 36322 & 0.0209361 & \mathrm{~K} \\ \mathrm{Mg}^{*} & 0.11 & 0.06 & 0.01 & 895 & 0.0002013 & \mathrm{~K} \\ \mathrm{Al} & 0.86 & 0.43 & 0.02 & 8731 & 0.0015705 & \mathrm{~K} \\ \mathrm{Si}^{*} & 0.24 & 0.11 & 0.01 & 2554 & 0.0004438 & \mathrm{~K} \\ \mathrm{~S}^{*} & 0.04 & 0.02 & 0.01 & 492 & 0.0001010 & \mathrm{~K} \\ \mathrm{Fe}^{*} & 0.41 & 0.10 & 0.02 & 1520 & 0.0009037 & \mathrm{~K} \\ \text { Total } & 100.00 & 100.00 & & & & \mathrm{~K}\end{array}$

(e)

(f)

Figure 9: SEM images of HMA at $150^{\circ} \mathrm{C}$ and optimized binder content of $4.23 \%$ : (a) asphalt mortar at magnification $\times 250$ and bar scale $100 \mu \mathrm{m}$. (b) Asphalt mortar at magnification $\times 300$ and bar scale $50 \mu \mathrm{m}$. (c) Filler particles at magnification $\times 5000$ and bar scale $5 \mu \mathrm{m}$. (d) Asphalt binder film at magnification $\times 10,000$ and bar scale $1 \mu \mathrm{m}$. (e) Asphalt binder film at magnification $\times 30,000$ and bar scale $0.5 \mu \mathrm{m}$. (f) Elemental composition of asphalt binder film at point $Y$ in image (e) by EDS.

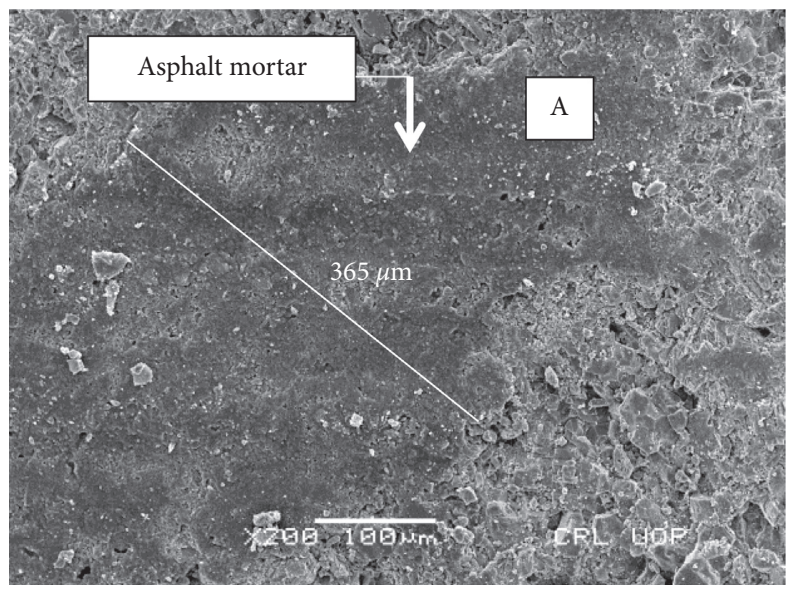

(a)

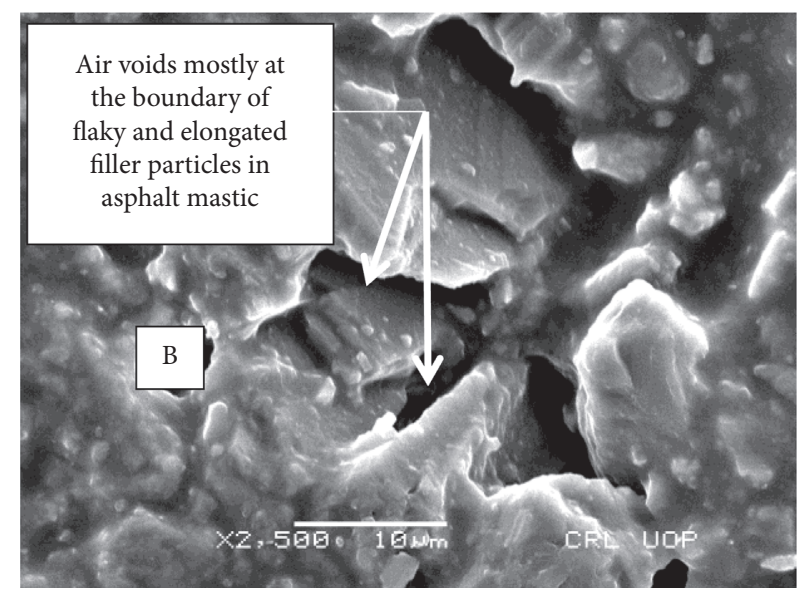

(b)

Figure 10: Continued. 


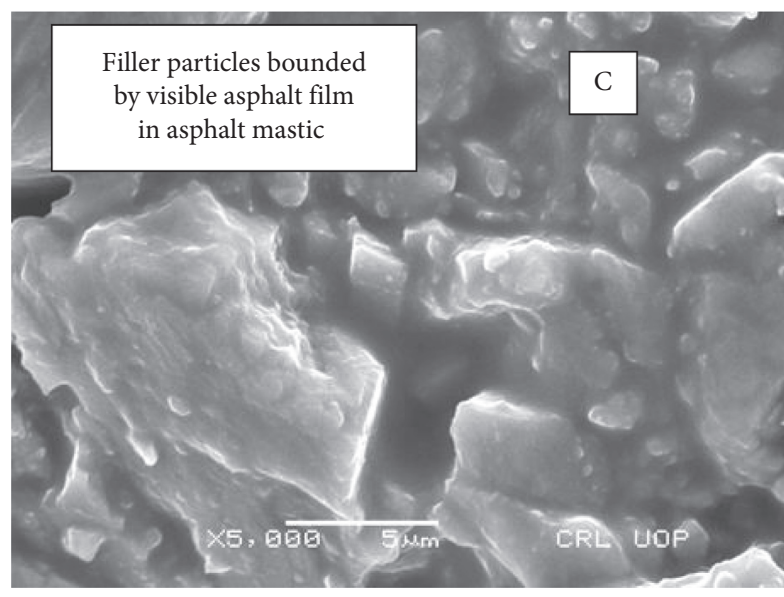

(c)

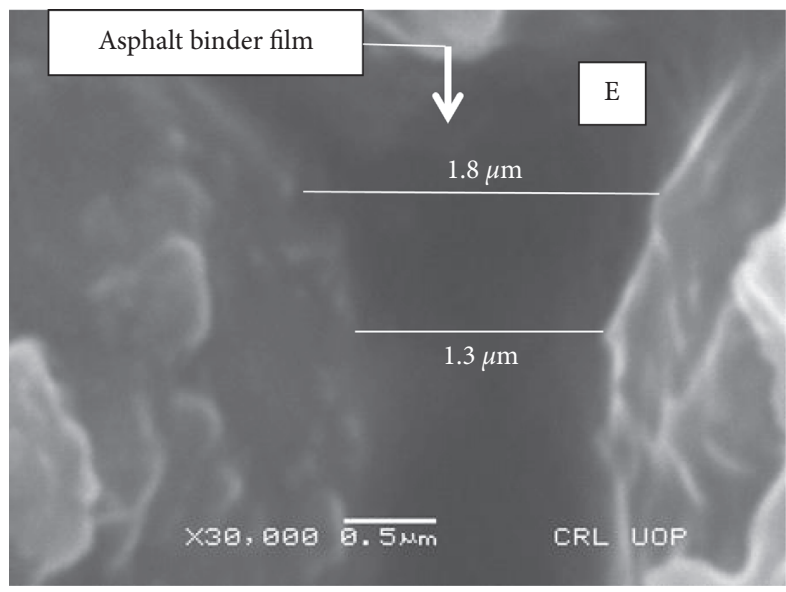

(e)

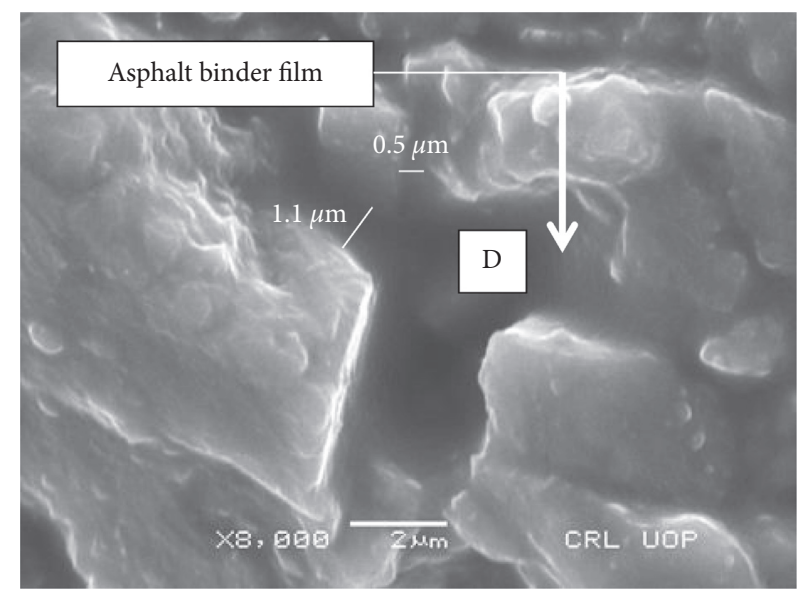

(d)

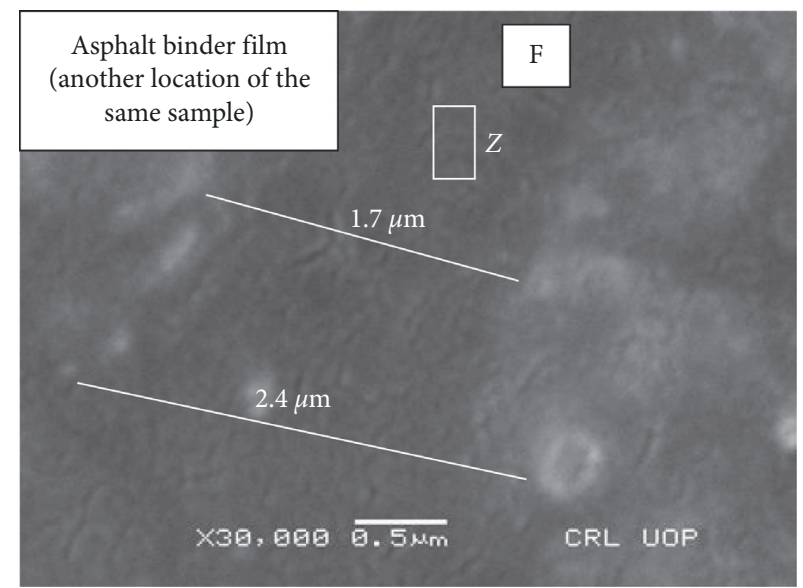

(f)

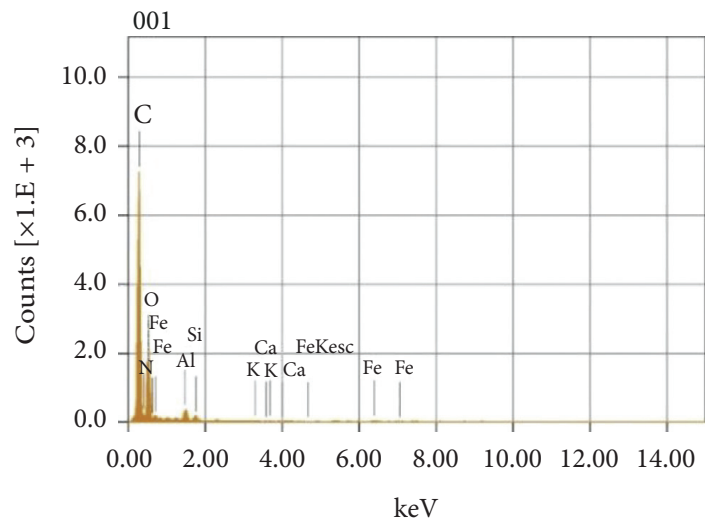

$\begin{array}{lcccccc}\text { Formula } & \text { Mass\% } & \text { Atom\% } & \text { Sigma } & \text { Net } & \text { K ratio } & \text { Line } \\ \mathrm{C} & 55.63 & 62.75 & 0.03 & 177670 & 0.0224099 & \mathrm{~K} \\ \mathrm{~N}^{*} & 1.99 & 1.93 & 0.02 & 7268 & 0.0124371 & \mathrm{~K} \\ \mathrm{O} & 40.93 & 34.66 & 0.13 & 53375 & 0.0307654 & \mathrm{~K} \\ \mathrm{Al} & 0.82 & 0.41 & 0.02 & 11215 & 0.0020173 & \mathrm{~K} \\ \mathrm{Si} & 0.38 & 0.19 & 0.01 & 5568 & 0.0009675 & \mathrm{~K} \\ \mathrm{~K}^{*} & 0.02 & 0.01 & 0.01 & 296 & 0.0000787 & \mathrm{~K} \\ \mathrm{Ca}^{*} & 0.04 & 0.01 & 0.01 & 574 & 0.0001605 & \mathrm{~K} \\ \mathrm{Fe}^{*} & 0.19 & 0.05 & 0.01 & 945 & 0.0005617 & \mathrm{~K} \\ \text { Total } & 100.00 & 100.00 & & & & \end{array}$

(g)

Figure 10: SEM images of HMA at $160^{\circ} \mathrm{C}$ and optimized binder content of $4.12 \%$ : (a) asphalt mortar at magnification $\times 200$ and bar scale $100 \mu \mathrm{m}$. (b) Voids in asphalt mastic at magnification $\times 2500$ and bar scale $10 \mu \mathrm{m}$. (c) Filler particles in mastic at magnification $\times 5000$ and bar scale $5 \mu \mathrm{m}$. (d) Asphalt binder film at magnification $\times 8000$ and bar scale $2 \mu \mathrm{m}$. (e) Asphalt binder film at magnification $\times 30,000$ and bar scale $0.5 \mu \mathrm{m}$. (f) Asphalt binder film at another location of the same sample at magnification $\times 30,000$ and bar scale $0.5 \mu \mathrm{m}$. (g) Elemental composition of asphalt binder film at point $Z$ in image (f) by EDS. 
and round particles, which reveals that mastic containing round particles does not have air voids because of liquid bitumen to mobilize round particles to fill voids if any, during compaction process, as shown in Figure 10(b). But the voids inside the mastic at the boundary of flaky and elongated filer particles have been observed which is contrary to the statement given by Kandhal and Chakraborty [14] that the voids do not exist in asphalt mastic and presented in Figure 10(b). Entities (filler particles) as small as $500 \mathrm{~nm}(0.5 \mu \mathrm{m})$ were observed when SEM images were taken at magnifications of $\times 5000$ and $\times 8000$ with a bar scale of $5 \mu \mathrm{m}$ and $2 \mu \mathrm{m}$ of the asphalt sample prepared at $140^{\circ} \mathrm{C}$, $150^{\circ} \mathrm{C}$, and $160^{\circ} \mathrm{C}$, as shown in Figures $8(\mathrm{c}), 9(\mathrm{c}), 10(\mathrm{c})$, and $10(\mathrm{~d})$, point $\mathrm{C}$. The asphalt binder film started appearing inside the asphalt mastic when the SEM images of the asphalt specimens prepared at various temperatures and binder contents were taken at magnifications of $\times 10,000$ and $\times 8,000$ with a bar scale of $1 \mu \mathrm{m}$ and $2 \mu \mathrm{m}$, respectively, as shown in Figures $8(\mathrm{~d}), 9(\mathrm{~d})$, and $10(\mathrm{~d})$, point $\mathrm{D}$. The asphalt binder film appeared very clearly inside the asphalt mastic in all types of asphalt samples when the SEM images were taken at magnification of $\times 30000$ with a bar scale of $0.5 \mu \mathrm{m}$, as shown in Figures 8(e), 9(e), 10(e), and 10(f), point E. The distance between two filler particles in the asphalt mastic, as shown in Figures 8(c), 8(d), 9(c), 9(d), 10(b), 10(c), and 10(d), is approximately ranging from 0.5 to 2.5 microns (nonabsorbed bitumen). This distance appears as pure asphalt binder film thickness. SEM measurements reveal that the asphalt binder film thickness in asphalt mixtures prepared at various temperatures and binder contents exist almost in the same limits, ranging from $0.5 \mu \mathrm{m}$ to $2.4 \mu \mathrm{m}$, as clearly observed in Figures 8(e), 9(e), 10(e), and 10(f). The elemental composition of the asphalt binder film was also obtained by EDS feature of SEM in order to assure the existence of pure asphalt binder film in asphalt mixtures, as presented in Figures 8(f), 9(f), and 10(g). The elemental composition of the asphalt binder film in all types of samples was carried out at particular points, as shown in Figures 8(e), 9(e), and 10(f), point $X, Y$, and $Z$.

All types of samples were analyzed in order to study the concept of asphalt binder film thickness and its relation to mixing temperature and binder content. The experimental study revealed that the microscopically measured values of film thickness under all conditions of temperature and optimized binder content vary from $0.5 \mu \mathrm{m}$ to $2.4 \mu$, without any relation to binder content and mixing temperature, as shown in Table 10 and Figures 8-10. On the contrary, the analytically estimated values of film thickness under all conditions of temperature and optimized binder content vary from $9 \mu \mathrm{m}$ to $13 \mu \mathrm{m}$ where the film thickness has fair relationship to binder content, mixing temperature, and model type as well. The analytical models, presented in Table 3, have been very effective but these models are based on some assumptions already described. Therefore, further study was explored in order to check the validity of asphalt binder film thickness by image analysis using SEM and EDS. On the basis of image analysis, a conversion factor of 0.120 was suggested and included in Table 7 in order to be multiplied with analytical models so that model's values can be compared to the measured values of film thickness using image analysis.

\section{Conclusions}

The main objective of the study was to investigate asphalt binder film thickness around the finest particles in asphalt mastic, using microlevel techniques at the highest magnifying power in order to check the validity of the conventional concept of asphalt binder film thickness and its relation to binder content and mixing temperature in HMA. The following conclusions have been drawn:

(i) The estimated values of asphalt binder film thicknesses using analytical models reveal that the film thickness is a function of temperature, binder content, and model type. For mix design at constant binder content and mixing temperature, a significant variation in asphalt binder film thickness has been observed. It is difficult to follow a particular limit in this case.

(ii) The analytical estimations revealed that the asphalt binder film thickness, under all conditions of temperature and binder contents, varies from $9 \mu \mathrm{m}$ to $13 \mu \mathrm{m}$, with a fair relationship to binder content and mixing temperature. However, results obtained from image analysis revealed that the asphalt binder film thickness varies from $0.5 \mu \mathrm{m}$ to $2.4 \mu \mathrm{m}$, with no relation to binder content and mixing temperature.

(iii) SEM study showed that the asphalt mixtures mostly contain asphalt mortar, ranging from $100 \mu \mathrm{m}$ to $365 \mu \mathrm{m}$, and bind the coarse aggregate in asphalt mixture. However, the asphalt mastic was found to be a two-phase system, containing bitumen and filler blended together, ranging up to $23 \mu \mathrm{m}$, and acts to grip fine aggregates in the asphalt mortar considered.

(iv) The asphalt binder film does exist as a separate entity only inside the asphalt mastic around the filler particles in the form of a band as a nonabsorbed binder, which fills the approximate distance of 0.5 to 2.5 microns among filler particles.

(v) The air voids exist at the interface between asphalt mortar and coarse particles and even inside the asphalt mastic at the boundary of flaky and elongated filler particle in asphalt mixtures considered.

\section{Notations}

SA: $\quad$ Aggregate surface area $\left(\mathrm{m}^{2} / \mathrm{kg}\right)$

$\rho_{b}: \quad$ Density of binder $\left(1027 \mathrm{~kg} / \mathrm{m}^{3}\right)$

$b$ : $\quad$ Binder content (\%)

$P_{i}: \quad$ Meter sieve residue percentage of various-sized particles on sieve $i(\%)$

$\mathrm{SAF}_{i}$ : $\quad$ Surface area factors of aggregates on sieve $i$

10: $\quad$ Conversion factor to convert $\mathrm{m}^{2} / \mathrm{kg}$ into $\mathrm{cm}^{2} / \mathrm{g}$

$W_{b}$ : Weight of binder $/ \mathrm{kg}$ of aggregate

$W_{\text {agg }}: \quad$ Weight of aggregate $(\mathrm{kg})$

$W_{s}: \quad$ Weight of aggregate $(\mathrm{g})$

$V_{b}$ : Volume of binder (\%)

$P_{b a}: \quad$ Percent of absorbed binder (\%) 
$P_{b e}: \quad$ Effective asphalt by total mix, \%

$G_{s e}: \quad$ Effective specific gravity of aggregate

$G_{s b}: \quad$ Bulk specific gravity of aggregate

$G_{b}: \quad$ Specific gravity of binder

$G_{m b}$ : Bulk specific gravity of compacted mixture

$G_{m m}$ : Maximum theoretical specific gravity of asphalt mixture

$P_{b}: \quad$ Asphalt binder by total mix (\%)

VFA: Voids filled with asphalt (\%)

VMA: Voids in mineral aggregate (\%)

VTM: Voids in total mix (\%)

ASP: Asphalt content of the mixture by dry weight of aggregate (\%)

BSG: Bulk specific gravity of the aggregates in the asphalt mixture

TMSG: Theoretical maximum specific gravity of the asphalt mixture

ASG: Specific gravity of the asphalt cement in the mixture

SEM: Scanning electron microscope

EDS: Energy dispersive X-ray spectroscopy.

\section{Data Availability}

The complete data are available within the article.

\section{Conflicts of Interest}

The authors declare that they have no conflicts of interest.

\section{References}

[1] F. L. Roberts, P. S. Kandhal, E. R. Brown, D. Lee, and T. W. Kennedy, Hot Mix Asphalt Materials, Mixture Design, and Construction, NAPA Education Foundation, Lanham, MD, USA, 2nd edition, 1996.

[2] G. G. Al-Khateeb, "Conceptualizing the asphalt film thickness to investigate the SuperPave VMA criteria," International Journal of Pavement Engineering, vol. 19, no. 11, 2016.

[3] G. G. Al-Khateeb and A. Shenoy, "Mixture-propertyindependent asphalt film thickness model," Materials Today Communications, vol. 19, pp. 482-486, 2017.

[4] M. Dong, W. Sun, L. Li, and Y. Gao, "Effect of asphalt film thickness on shear mechanical properties of asphalt-aggregate interface, construction and building materials," Construction and Building Materials, vol. 263, no. 1, Article ID 120208, 2020.

[5] M. Dong, Y. Hao, C. Zhang, L. Li, W. Sun, and C. Jin, "Shear fracture energy of asphalt-aggregate systems and its application to predicting shear fatigue in asphalt mixtures," International Journal of Pavement Engineering, vol. 21, no. 2, pp. 246-256, 2020.

[6] M. Dong, Y. Hao, C. Zhang, and L. Li, "Failure mechanism analysis of asphalt- aggregate systems subjected to direct shear loading," Materials and Structures, vol. 50, no. 5, p. 218, 2017.

[7] A. Noory, F. M. Nejad, and A. Khodaii, "Effective parameters on interface failure in a geocomposite reinforced multilayered asphalt system," Road Materials and Pavement Design, vol. 19, no. 6, pp. 1458-1475, 2018.

[8] M. Barman, J. M. Vandenbossche, and Z. Li, "Influence of interface bond on the performance of bonded concrete overlays on asphalt pavements," The Journal of Transportation Engineering, Part B: Pavements, vol. 143, no. 3, 2017.

[9] J. Yi, S. Shen, and D. Wang, "Characterization of the bonding fracture properties of the asphalt-aggregate system using a thin-film interface test," Journal of Testing and Evaluation, vol. 44, pp. 450-460, 2016.

[10] A. Cala, S. Caro, M. Lleras, and Y. Rojas-Agramonte, "Impact of the chemical composition of aggregates on the adhesion quality and durability of asphalt-aggregate systems," Construction and Building Materials, vol. 216, pp. 661-672, 2019.

[11] N. AlKofahi and T. Khedaywi, "Evaluation the effect of asphalt film thickness on stripping resistance," International Journal of Applied Engineering Research, vol. 14, no. 2, pp. 560-570, 2019.

[12] P. S. Kandhal, K. Y. Foo, and R. B. Mallick, "A critical review of VMA requirements in superpave mix design," NCAT Report 98-01, National Center for Asphalt Technology, Auburn, Alabama, 1998.

[13] N. W. McLeod, Voids Requirements for Dense-Graded Bituminous Paving Mixtures, ASTM, West Conshohocken, PA, USA, 1959.

[14] P. S. Kandhal and S. Chakraborty, "Evaluation of voids in the mineral aggregate for HMA paving mixtures," NCAT Report 96-4, National Center for Asphalt Technology, Auburn, Alabama, 1996.

[15] B. Sengoz and E. Agar, "Effect of asphalt film thickness on the moisture sensitivity characteristics of hot-mix asphalt," Building and Environment, vol. 42, no. 10, pp. 3621-3628, 2007.

[16] M. Heitzman, "New film thickness models for Iowa hot mix asphalt," in Proceedings of the Mid-Continent Transportation Research Symposium, Iowa State University, Ames, Iowa, 2007.

[17] J. W. Oliver, "The effect of binder film thickness on asphalt cracking and ravelling," Road and Transport Research, vol. 20, no. 3, pp. 3-13, 2011.

[18] Asphalt Institute, Mix Design Methods for Asphalt Concrete (MS-02), Asphalt Institute, Lexington, KY, USA, 2nd edition, 1963.

[19] J. Read and D. Whiteoak, The Shell Bitumen Handbook, Calculation of Bitumen Film Thickness in Asphalt Mixtures, Shell UK Oil Products Limitted, London, UK, 2015.

[20] L. Debao, H. Xiaoming, and G. Changlu, "Method to determine asphalt film thickness based on actual measurement," Advanced Materials Research, vol. 779-780, pp. 140-143, 2013.

[21] J. P. Zaniewski and C. H. Reyes, Evaluation of the Effect of Fines on Asphalt Concrete, Asphalt Technology Program, Department of Civil and Environmental Engineering, Morgantown, WV, USA, 2003.

[22] Overseas Road Note 19, A Guide to the Design of Hot Mix Asphalt in Tropical and Sub-tropical Countries, TRL Limited, Crowthorne, UK, 1st edition, 2002.

[23] Asphalt Institute, SuperPave Mix Design Series No. 2 (SP-2), Asphalt Institute, Lexington, KY, USA, 3rd edition, 2001.

[24] American Society for Testing and Materials, ASTM C131, Standard Test Method for Resistance to Degradation of SmallSize Coarse Aggregate by Abrasion and Impact in the Los Angeles Machine, ASTM International, West Conshohocken, PA, USA, 2020.

[25] British Standard Institute, BS EN 933-3, Standard Test Method for Determination of Particle Shape. Flakiness Index of Coarse Aggregate, British Standard Institute, London, UK, 2012. 
[26] American Society for Testing and Materials, ASTM D4791-19, Standard Test Method for Flat Particles, Elongated Particles, or Flat and Elongated Particles in Coarse Aggregate, ASTM International, West Conshohocken, PA, USA, 2019.

[27] American Society for Testing and Materials, ASTM D5821-13, Standard Test Method for Determining the Percentage of Fractured Particles in Coarse Aggregate, ASTM International, West Conshohocken, PA, USA, 2017.

[28] American Society for Testing and Materials, ASTM D2419-14, Standard Test Method for Sand Equivalent Value of Soils and Fine Aggregate, ASTM International, West Conshohocken, PA, USA, 2014.

[29] American Society for Testing and Materials, ASTM C127-15, Standard Test Method for Relative Density (Specific Gravity) and Absorption of Coarse Aggregate, ASTM International, West Conshohocken, PA, USA, 2015.

[30] American Society for Testing and Materials, ASTM C88-13 Standard Test Method for Soundness of Aggregates by Use of Sodium Sulfate or Magnesium Sulfate, ASTM International, West Conshohocken, PA, USA, 2013.

[31] American Society for Testing and Materials, ASTM C1252-17, Standard Test Methods for Uncompacted Void Content of Fine Aggregate (As Influenced by Particle Shape, Surface Texture, and Grading), ASTM International, West Conshohocken, PA, USA, 2017.

[32] American Society for Testing and Materials, ASTM C586-19, Standard Test Method for Potential Alkali Reactivity of Carbonate Rocks as Concrete Aggregates (Rock-Cylinder Method), ASTM International, West Conshohocken, PA, USA, 2019.

[33] American Society for Testing and Materials, ASTM C295-19, Standard Method for Petrographic Examination of Aggregates for Concrete, ASTM International, West Conshohocken, PA, USA, 2019.

[34] F. Malahat, A. Naseer, and R. Bilqees, "Engineering and mineralogical assessment of coarse aggregates used in district mardan," Journal of Himalayan Earth Sciences, vol. 51, no. 1, pp. 34-43, 2018.

[35] American Society for Testing and Materials, ASTM D5/D5M20, Standard Test Method for Penetration of Bituminous Materials, ASTM International, West Conshohocken, PA, USA, 2020.

[36] American Society for Testing and Materials, ASTM D36/ D36M-14, Standard Test Method for Softening Point of Bitumen (Ring-And-Ball Apparatus), ASTM International, West Conshohocken, PA, USA, 2020.

[37] American Society for Testing and Materials, ASTM D113-17, Standard Test Method for Ductility of Asphalt Materials, ASTM International, West Conshohocken, PA, USA, 2017.

[38] American Society for Testing and Materials, ASTM C142/ C142M-17, Standard Test Method for Clay Lumps and Friable Particles in Aggregates, ASTM International, West Conshohocken, PA, USA, 2017.

[39] American Society for Testing and Materials, ASTM D4402/ D4402M-15, Standard Test Method for Viscosity Determination of Asphalt at Elevated Temperatures Using a Rotational Viscometer, ASTM International, West Conshohocken, PA, USA, 2017.

[40] American Society for Testing and Materials, ASTM D7175-15, Standard Test Method for Determining the Rheological Properties of Asphalt Binder Using a Dynamic Shear Rheometer, ASTM International, West Conshohocken, PA, USA, 2015.

[41] American Society for Testing and Materials, ASTM D6373-16, Standard Specification for Performance Graded Asphalt
Binder, ASTM International, West Conshohocken, PA, USA, 2016.

[42] American Society for Testing and Materials, ASTM D1559, Resistance to Plastic Flow of Bituminous Mixtures using Marshall Apparatus, ASTM International, West Conshohocken, PA, USA, 1989.

[43] American Society for Testing and Materials, ASTM D2041 / D2041M-19, Standard Test Method for Theoretical Maximum Specific Gravity and Density of Asphalt Mixtures, ASTM International, West Conshohocken, PA, USA, 2019. 